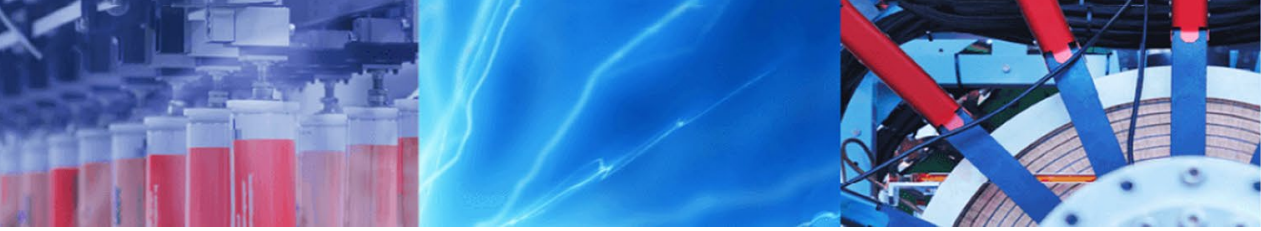

Research Article

\title{
Artificial neural networks and adaptive neuro-fuzzy models for predicting WEDM machining responses of Nitinol alloy: comparative study
}

\author{
C. Naresh ${ }^{1}$ (D) P. S. C. Bose ${ }^{1}$. C. S. P. Rao ${ }^{2}$
}

Received: 2 October 2019 / Accepted: 21 January 2020 / Published online: 31 January 2020

(c) Springer Nature Switzerland AG 2020

\begin{abstract}
This article reports a comparative study of artificial neural network (ANN) and adaptive neuro-fuzzy inference system (ANFIS) models for better prediction of wire electro-discharge machining (WEDM) responses like material removal rate and surface roughness of a Nitinol alloy. Pulse on time $\left(T_{\text {on }}\right)$, pulse off time $\left(T_{\text {off }}\right)$, peak current $\left(I_{\text {peak }}\right)$ and gap voltage (V) were selected as input attributes. Experimental results were performed to verify the results from ANN and ANFIS models. ANN model, back-propagation with three different algorithms Levenberg-Marquardt (LM), Elman regression neural network and generalized regression neural network and ANFIS model, were developed using the same input variables. The most suitable algorithm and neuron number in the hidden layer were found as LM with 10 neurons for ANN models whereas the most suitable membership functions and number of membership functions are found to be gauss and two, respectively. The statistical validation measures such as root mean square error, mean square error and mean absolute percentage error are obtained through ANN and ANFIS models. The statistical values are given in the tables. As per the statistical measures perspective, the ANFIS model will have better accuracy for anticipation of WEDM attributes of a Nitinol alloy.
\end{abstract}

Keywords ANN · ANFIS $\cdot$ Nitinol $\cdot$ MRR $\cdot$ Surface roughness $\cdot$ WEDM

\section{Introduction}

Aerospace industry is looking at developing novel materials by incorporating features like superior strength-toweight ratio, superior mechanical strength, excellent corrosion resistance, etc. in alloys. Nickel titanium (Nitinol) alloy is one of the upcoming novel materials with properties such as better strength-to-weight ratio, high ductility, more resistance to wear and corrosion, excellent biocompatibility, etc. [1]. The addition of a ternary alloying element like copper leads to increase in transformation temperatures, quick actuating response, fatigue and damping properties [2]. In addition to this, this material also acquires two outstanding distinct properties like shape memory and super elasticity, leading to several applications in automotive and medical industries. Nitinol alloy belongs to difficult-to-cut materials due to low thermal conductivity and modulus of elasticity, high strain hardening and is exceptionally hard to machine using regular machining forms like turning, boring, milling and so on, to avoid extreme tool wear as well as chips adhering to the tool, etc. [3] researchers are looking at non-traditional machining processes such as electro-chemical machining (ECM), electro-discharge machining (EDM), abrasive jet machining (AJM) wire electro-discharge machining (WEDM), laser machining, hybrid machining processes, etc. wire electrodischarge machining is a standout process amongst the most versatile un-traditional machining procedures to

C. Naresh, nareshhbk@gmail.com | ${ }^{1}$ National Institute of Technology, Warangal 506004, India. ${ }^{2}$ National Institute of Technology, Tadepalligudem, Andhra Pradesh 534101, India. 
machine hard metals and combinations of metals like nickel-based alloys, titanium-based alloys, shape memory alloys, strain hardened materials, etc. In WEDM, metal expulsion is influenced by start disintegration, since the wire is bolstered through work piece [4] where ordinarily used wires are made of copper, brass, aluminium, molybdenum and graphite. The use of copper as wire leads to increase in surface hardness because of the development of titanium carbide. Graphite has high melting point due to which its material removal rate is greater while aluminium gives good surface finish $[5,6]$. Worked on WEDM characteristics of input attributes on MRR and SR of $\mathrm{Ti}_{50} \mathrm{Ni}_{42.4} \mathrm{Cu}_{7.6}$ shape memory alloys. Conjunction of small peak current with little $T_{\text {on }}$ is more advantageous to maximize MRR while minimizing SR high $T_{\text {on }}$ with small current is essential [7] and reports the impact of WEDM process attributes on machined surface of $\mathrm{Ti}_{50} \mathrm{Ni}_{49} \mathrm{Co}_{1}$ shape memory alloy. Indigent surface quality was noticed at greater $T_{\text {on }}$ while superior surface roughness was obtained at higher Servo Voltage [8]. Suggested a fuzzy adaptive controller and used a fuzzy imperialist competitive algorithm to handle the complexity in resolving typical optimization problems in manufacturing. Artificial neural network along with genetic algorithm was applied for improving surface texturing properties of EN 31 steel during WEDM process [9]. Responses like MRR and surface roughness are predicted and analysed parametrically using ANFIS modelling during turning of 202 stainless steel [10, 11]. It is proposed that comparative analytical models rely on neural network back-propagation along with ANFIS and RSM for predicting MRR and SR all along with helium-assisted electrodischarge machining of die steel. An ANFIS modified system was proposed to optimize the active parameters and grinding effectiveness in bearing manufacturing to achieve better productivity compared with other practices $[12,13]$. Determined the impact of WEDM attributes on performance attributes to enhance the efficiency with superior quality of titanium alloy (Ti-6Al-4V) utilizing ANFIS and grey relation analysis (GRA) approach. Artificial intelligence techniques like ANFIS and artificial neural networks are implemented to anticipate tool wear during conventional milling of aluminium alloy composites [14]. ANFIS combined with Gaussian regression function and Taguchi analysis was adopted for online prophecy of SR and grinding wheel wear all through the grinding of Ti-6Al-4V [15]. Neural networks and fuzzy inference system (FIS) optimized models were evolved for determining ultimate tensile strength of friction stir welded aluminium alloy joints [16]. ANN models were developed for predicting WEDM responses of aluminium-based metal matrix composites [17]. Hybrid techniques of artificial neurofuzzy and ANN were adopted for the prediction of machining characteristics of Ti-6Al-4V alloy $[18,19]$ attempted back-propagation neural network model for anticipation of SR during the turning of mild steel work pieces. A multistage decision algorithm was designed based on ANN and ANFIS models for detection and diagnosis of bearing faults [20]. Prediction of machining responses like tool wear and SR was done during the turning of steel under minimum quantity of lubrication using artificial neural network [21]. Various neural network models on MRR were compared during electrical discharge machining process and it was concluded that ANFIS with bell-shaped function gives the best predicted model [22]. For obtaining greater productivity and good product quality during industrial automation, tool wear prediction was made through a combination of radial basis functions and neural fuzzy function [23]. Experimental investigations was carried out to examine the effect of input attributes on SR and cutting force components during hard turning of American Iron and Steel Institute (AISI) 420, which also predicted machining responses using RSM and ANN [24]. Laser cutting roughness is predicted using ANFIS intelligent model which combines adaptive learning ability with FIS for improving the quality of laser cutting [25]. A hybrid method of orthogonal-based ANN and multi-genetic algorithm is adopted for optimization during wire electro-discharge machining of Ti-48Al intermetallic alloy $[26,27]$ compared ANN and ANFIS models for estimating the performance of solar-assisted ground source heat pump system [28] demonstrated the usefulness of adaptive neuro-fuzzy inference system, especially hybrid learning algorithm used for modelling the ground coupled heat pump system more accurately [29] has made a comparative study of ANN and ANFIS models for modelling and predicting a ground coupled heat pump system [30] used ANN with statistical weighted preprocessing technique for predicting and improving the performance of ground source heat pump systems. Application of artificial neural networks was adopted for predicting the horizontal ground coupled heat pump systems [31]. Performance of a ground source heat pump prediction based on ANFIS with a fuzzy weighted preprocessing technique was adopted. Finally, based on the results, the proposed fuzzy weighted preprocessing-based ANFIS gives better accuracy than standard ANFIS results [32,33]. A modelling study of solar air heater using ANN and wavelet neural network modelling approaches for evaluating the performance of a new solar air heater is reported. Application of ANN model with three different learning algorithms, Levenberg-Marquardt (LM), Scaled Conjugate Gradient (SCG) and Pola-Ribiere Conjugate Gradient (CGP) algorithms and ANFIS model were developed using the same input variables for predicting the performance of vertical ground source heat pump [34, 35] developed ANN model for prediction of surface roughness in WEDM of Inconel 825 aerospace alloy. The 
Table 1 Chemical constitution of Nitinol alloy

\begin{tabular}{llllllllll}
\hline Element & $\mathrm{Ni}$ & $\mathrm{Ti}$ & $\mathrm{Cu}$ & \multicolumn{1}{c}{$\mathrm{C}$} & $\mathrm{O}$ & $\mathrm{Al}$ & $\mathrm{Si}$ & $\mathrm{S}$ & $\mathrm{Fe}$ \\
\hline Weight (\%) & 45.10 & 43.72 & 6.35 & 2.95 & 1.45 & 0.16 & 0.16 & 0.03 & 0.08 \\
Atomic (\%) & 36.04 & 42.83 & 4.69 & 11.51 & 4.27 & 0.27 & 0.26 & 0.05 & 0.06 \\
\hline
\end{tabular}

performance of solar chimney power plants were identified and modelled by using ANN and ANFIS models [36]. ANN and ANFIS models were compared for predicting surface roughness of assisted electrical discharge machining of D3 steel [37]. Application of artificial neural network computing technique was adopted for predicting the depth and surface roughness in laser milling of polymethyl-methacrylate [38]. Hence, it is apparent from earlier studies that only limited studies on the prediction of WEDM output attributes of a Nitinol alloy through artificial intelligent techniques have beencarried out. The present article is therefore an attempt to predict WEDM response attributes like MRR and SR of Nitinol alloy while comparing two models based on statistical errors and accuracy. In this study, experiments were designed using central composite face-centred design by considering pulse on time $\left(T_{\text {on }}\right)$, pulse off time $\left(T_{\text {off }}\right)$, peak current $\left(I_{\text {peak }}\right)$ and gap voltage $(\mathrm{V})$ as input attributes, while $S R$ and MRR were output attributes for WEDM of a Nitinol alloy. Two artificial adaptive models-neural networks and adaptive neuro-fuzzy inference system are explored to predict output attributes of a work piece for a variety of input attributes.

\section{Materials and methods}

Nitinol alloy (nickel titanium alloy) is commercially available and is supplied by Kellogg's Research Labs, United States of America (USA), and was used as work piece material for machining. It has a melting point of around $1300 \pm 50^{\circ} \mathrm{C}$ and density of $6.45 \mathrm{gm} / \mathrm{cm}^{3}$.

\subsection{Energy-dispersive X-ray fluorescence (EDXRF) of a Nitinol alloy}

The chemical constitution of the workpiece is provided by the supplier and confirmed by energy-dispersive $X$-ray fluorescence (EDXRF) analyser (VEGA 3LMU.TESCAN, Czech Republic) shown in Table 1, as illustrated in Fig. 1. It shows the presence of different chemical elements such as carbon $(\mathrm{C})$, oxygen $(\mathrm{O})$, aluminium $(\mathrm{Al})$, silicon $(\mathrm{Si})$, sulphur (S) and iron (Fe).

\subsection{Microstructure of Nitinol alloy}

Figure 2 shows the microstructure of Nitinol alloy. In this technique, the surface of the specimen should be cleaned

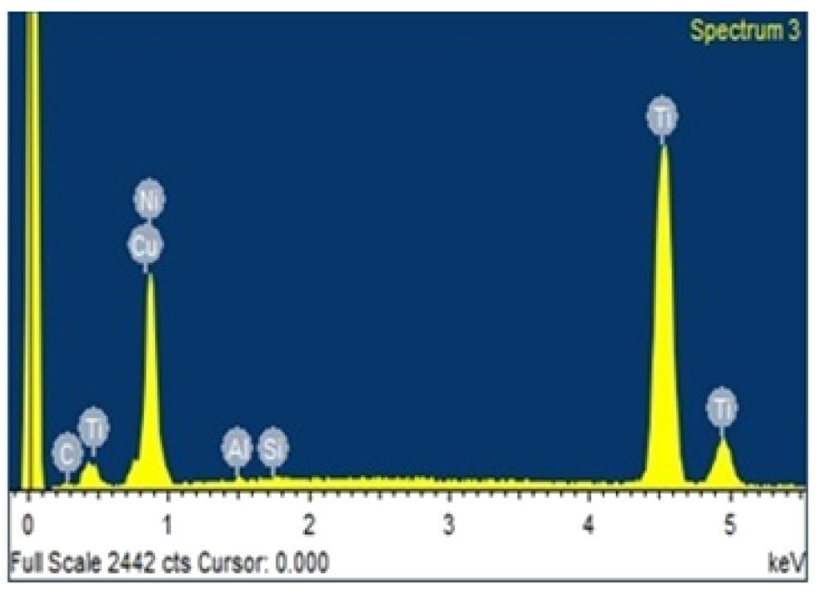

Fig. 1 EDXRF analysis for Nitinol alloy

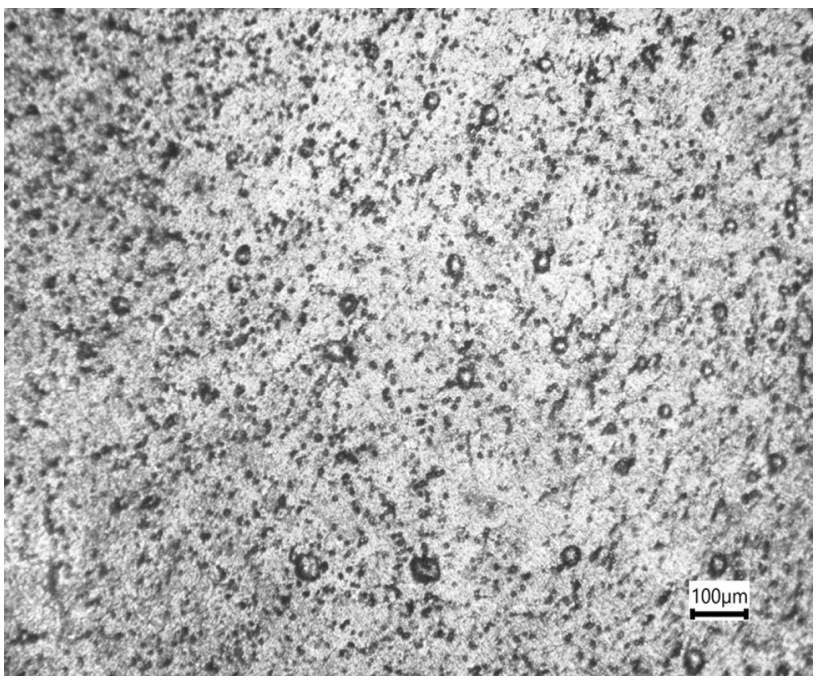

Fig. 2 Microstructure of Nitinol alloy before machining

with polishing techniques to obtain mirror surface. Etchants were finally adopted for Nitinol alloy to obtain different phases of crystal structure. From this analysis, it is observed that the dark phase is identified as nickel titanium (NiTi) and bright phase as $\mathrm{Ti}_{2} \mathrm{Ni}$ and copper and $\mathrm{Fe}$ atoms were also present in the matrix of both phases. 


\subsection{Differential scanning calorimetry (DSC) of a Nitinol alloy}

Differential scanning calorimetry (DSC) analysis is the most commonly adopted thermal analysis technique for measuring transformation temperatures. It measures the amount of energy absorbed or released by a sample when it is heated or cooled. DSC curve was observed for Nitinol alloy and the transformation temperatures were analysed using tangent method as shown in Fig. 3.

From DSC Curve, we analyse the transformation temperatures using tangent method. Martensite start temperature $\left(M_{\mathrm{s}}\right)=42.64^{\circ} \mathrm{C}$; martensite finish temperature $\left(M_{\mathrm{f}}\right)=13.97^{\circ} \mathrm{C}$; austenite start temperature $\left(A_{\mathrm{s}}\right)=49.126^{\circ} \mathrm{C}$; austenite finish temperature $\left(A_{\mathrm{f}}\right)=78.21^{\circ} \mathrm{C}$.

\subsection{Artificial neural networks}

Artificial neural network is the most extensively adopted model for addressing complex and nonlinear problems. It is the preferred model to explain complex behaviour between input and output in WEDM process. It has been used extensively in numerous fields such as process modelling, robotics, pattern recognition, forecasting, etc. [39, 40]. A basic model of ANN comprises three layers: input, hidden and output. The pairs of input-output patterns are stocked in input and output layers, the hidden layer relates to the distinguished strength of data from the input to output patterns, through so-called weights. The weights are altered in the learning process in which all the layers of input-output are presented in the learning phase frequently. For training multi-layer network, a lot of algorithms are available, the most commonly accepted learning algorithm being back-propagation algorithm. The general architecture of back-propagation neural network constitutes input, hidden and output layers, as shown in Fig. 4. The input layer takes data from exterior sources and advances this data to the network for processing. The hidden layer takes data from the input layer, and does whole data processing, and the output layer takes treated data from the network, and transmit the results out to an exterior receptor. Cluster type of superintend learning has been used in the current case, where, whole input-output pattern sets are furnished to the neural network step by step, and again modified using average gradient data. During training, the evaluated output is correlated with the target output, and the mean square error is determined. If the mean square error is greater than the recommended restricting value of the error, it is back-propagated to change the concatenation weights

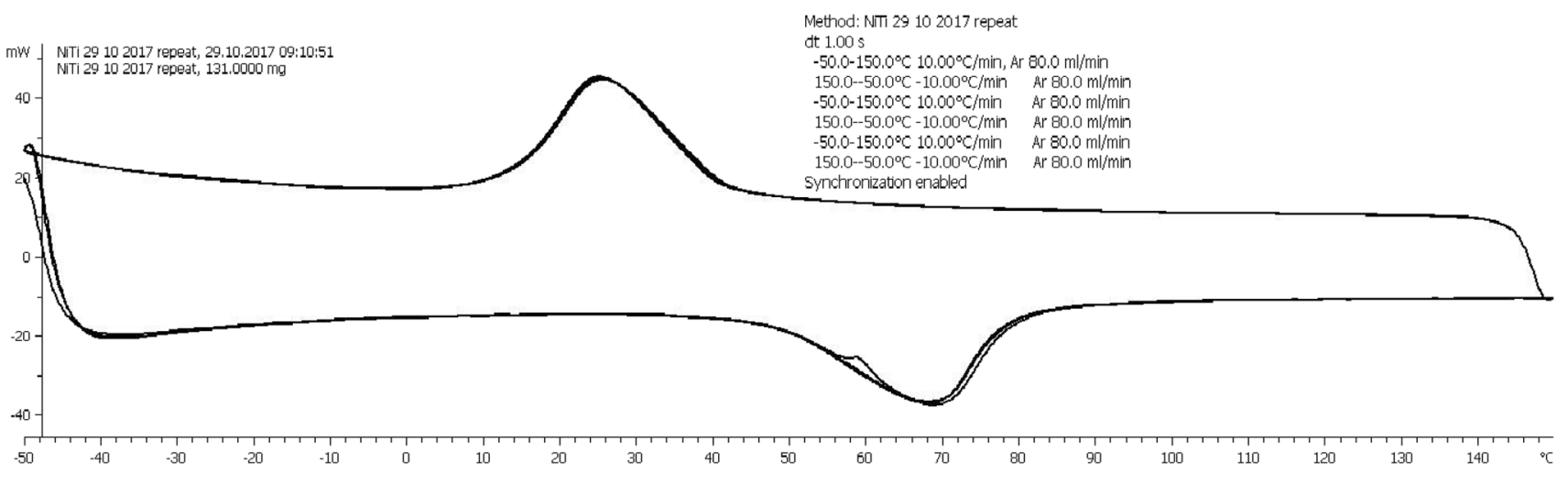

Fig. 3 DSC curve of a Nitinol alloy

Fig. 4 Multi-layer neural network architecture for both MRR and SR

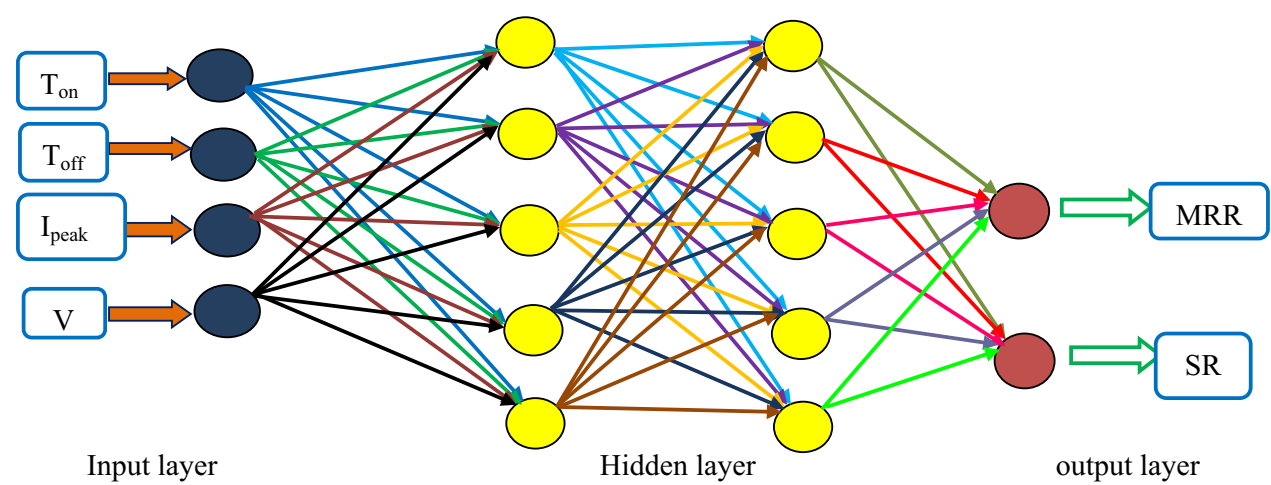

Hidden layer output layer 
and the process continues until the recommended error rein is arrived.

Mean square error, $E$, is calculated by Eq. (1)

$E=\frac{1}{P} \sum_{1}^{P} \sum_{k=1}^{n}\left(d_{k}^{p}-c_{k}^{p}\right)^{2}$

where $p=$ number of pattern, $n=$ number of node in output layer, $d_{k}^{p}=$ desired output of $k$ th node of $p$ th pattern, $c^{p}$ $k=$ calculated output of $k$ th node of $p$ th pattern.

Figure 5 shows the framework of ANN model.
To accomplish ANN model for prediction of MRR and SR, the following points are followed in the sequence below

1. Collect experimental data.

2. Divide the experimental data into training and testing data sets.

3. Create a network by giving training and testing sample.

4. Configure the network by choosing the number of hidden layers and required training, transfer and learning functions.

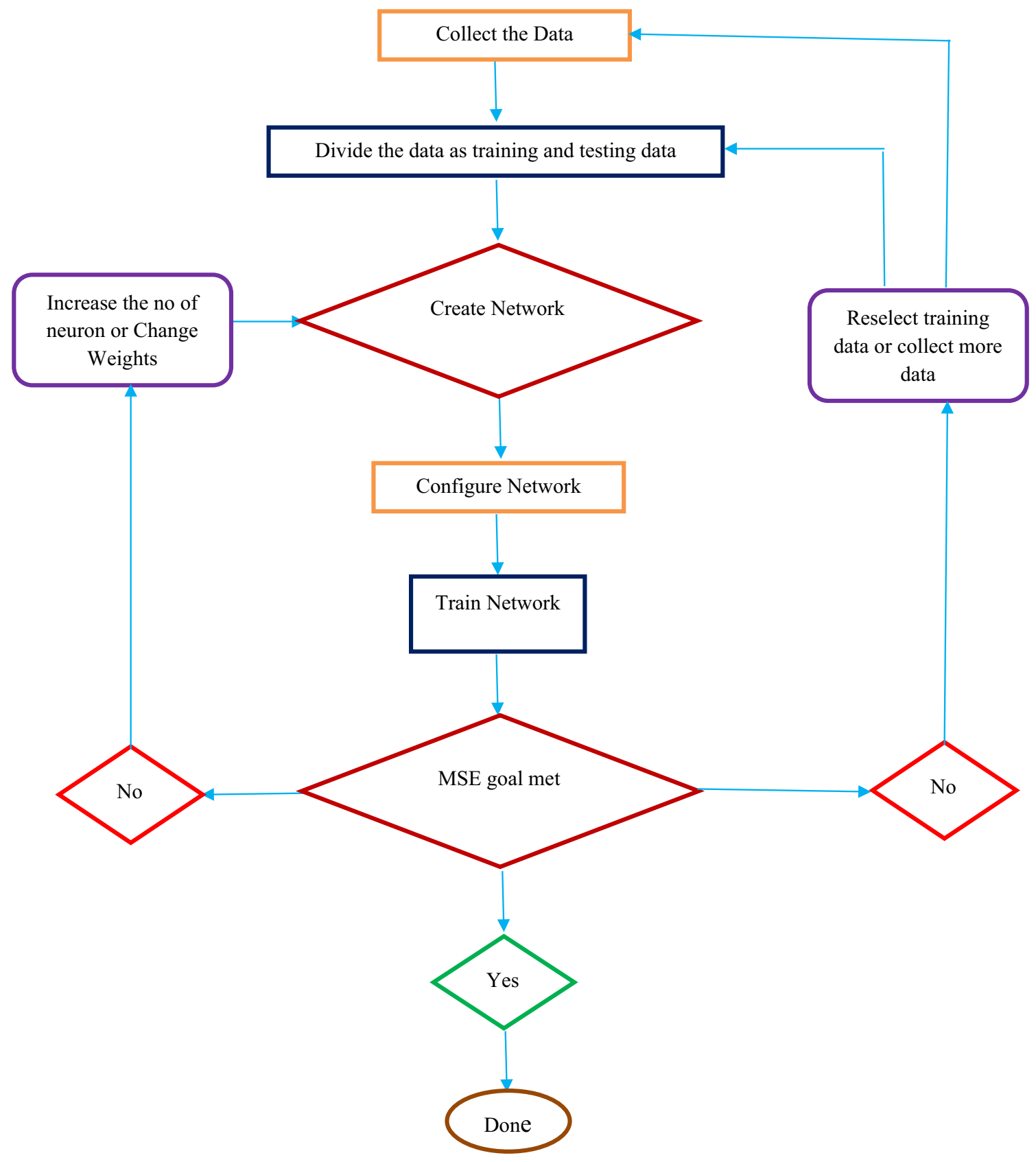

Fig. 5 Framework of ANN model 
5. Train the ANN model by giving it the required parameters to achieve MSE goal.

6. If the attempt results in failure, go back to change the hidden layers or weights and generate the network again and repeat the cycle until the required goal is achieved.

\subsection{Adaptive neuro-fuzzy inference system}

ANFIS is a hybrid conjecturing model which combines neural network and fuzzy logic to develop mapping connection between inputs and outputs [41]. In the hybrid approach, the neural network is trained by data while fuzzy logic is based on linguistic rules called If-then rules. If-then rules are incorporated along with trained data and are called inference of fuzzy inference system. Fuzzy systems and neural networks are amongst the most important soft computing methods. The connection between neural networks and linguistic knowledge-based system is bidirectional and has been discussed extensively [42]. The ANFIS model gives overall behaviour of Input or output obtained by a collection of variables [43]. The goal of ANN and fuzzy systems are to follow the actions of an expert for resolving a complex problem through instruction or learning. If one has data instruction or can learn from simulation or real problem, ANN is highly suitable. If one gains learning from knowledge expressed in the form of linguistic rules, one can build a fuzzy system. The advantages of both fuzzy and ANN systems are combined in a neuro-fuzzy approach called ANFIS [44].

The goal is to establish an adaptive neuro-fuzzy inference model to correlate the inputs to the output attributes perfectly. They are assessed on the basis of testing accomplishment. An ANFIS model is developed for predicting the wire electro-discharge machining responses like material removal rate and SR. In this research, a total of 100 data patterns were used for the prediction of ANFIS model. In general, total data instances are divided into training and testing data sets. The training data set is mainly adopted for building ANFIS model as long as the testing data sets are used for validating the predicted model.
ANFIS structure is categorized into five layers in which each layer is erected by various nodes as in a neural network. (1) Input data fuzzification, (2) fuzzy database structure, (3) structure of fuzzy rule base, (4) preparation for decision and (5) output defuzzification [45]-simplified ANFIS illustration are shown in Fig. 6.

To illustrate this model clearly, the five layers of ANFIS network contain two inputs ( $x$ and $y$ ) with two fuzzy rules and output attribute $f$. The inputs of individual layers in the structure are acquired by the nodes from prior layer. ANFIS rule base constitutes If-then rules of the fuzzy Sugeno type. For a first-order Sugeno fuzzy inference system (FIS), two rules may be given as

Rule 1 If $x$ is $A_{1}$ and $y$ is $B_{1}$, then $f$ is $f_{1}(x, y)$

Rule 2 If $x$ is $A_{2}$ and $y$ is $B_{2}$, then $f$ is $f_{2}(x, y)$,

$x, y$ are ANFIS inputs, $A_{j}, B_{i}$ are the fuzzy sets, $f_{1}(x, y)$ are the output of the first-order Sugeno FIS. The simplified ANFIS structure is shown in Fig. 6. The attributes sets that are flexible in these nodes are given by adoptive nodes indicated by squares, while firm nodes are indicated by circles [46].

ANFIS model for both MRR and SR comprises five layers of adaptive network which consists of four inputs with eight fuzzy rules with one output Inference system is assembled by five layers, where every layer constitutes various nodes characterized by node function. The current layer inputs are obtained from earlier layers. The ANFIS rule base generally contains If-then rules of Sugeno type [48].

Primary layer is the fuzzy layer, which gives information about adaptive nodes with node functions $i$. The membership connection between the output and input functions of this layer are given by:

$Q_{1, i}=\mu_{A i}(x) \quad(i=1,2)$

$Q_{1 i j}=\mu_{B i}(y) \quad(i=3,4)$

$Q_{1 i}$ and $Q_{1 i j}$ stand as output functions and $\mu_{\mathrm{Ai}}$ and $\mu_{\mathrm{Bj}}$ are designates of membership functions. There are various membership functions such as trigonometric, triangular, trapezoidal, bell mf, gauss mf types, which are generally
Fig. 6 Simplified ANFIS structure [47]

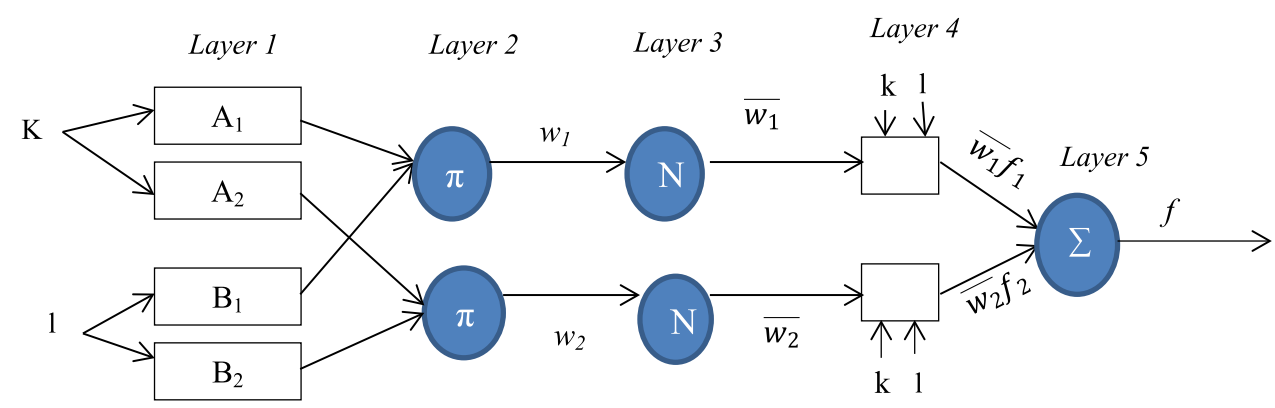


adopted. Amongst all types gauss membership function is preferred to show the linguistic labels because the connection between processing time and make span is nonlinear and this gives a smooth transition.

It may be written as.

Initial parameter membership function

$$
\begin{aligned}
& \mu_{A i}(x)=\exp \left[-0.5\left(\frac{\left(x-a_{i 1}\right)}{b_{i 1}}\right) 2\right] \\
& \mu_{B i}(y)=\exp \left[-0.5\left(\frac{x-a_{i 2}}{b_{i 2}}\right) 2\right]
\end{aligned}
$$

Layer 2 consists of fixed nodes indicated by a circle. A node function multiplied by input gives output. For each node, this type of layer is called rule node. It evaluates the firing strength of the correlated rule.

$Q_{2, i}=w_{i}=\mu_{A i}(x) \mu_{B i}(y)$

here $Q_{2, i}$ denotes the output of the second layer.

In the third layer, every node $i$ is considered firm node and is indicated by circles and labelled $N$ which gives the normalization of the firing levels. Its purpose is to normalize the weight function in the following process:

$Q_{3, i}=\bar{w} \frac{w_{i}}{\sum w_{i}} \quad(i=1,2)$

where $Q_{3, i}$ signifies the output of the third layer

Layer 4 is called de-fuzzy layer, whose node $i$ is adaptive and indicated by a square. If the output equation is $\bar{w}$, the de-fuzzy connection between the input and output of this layer may be defined as:

$Q_{4}, i=\bar{w}_{i} \times f_{i} \quad(i=1,2)$

where $Q_{4}, i$ signifies the output of the fourth layer, where $f_{1}$ and $f_{2}$ are the fuzzy If-then rules are as follows

Rule 1 If $x$ is $A_{1}$ and $y$ is $B_{1}$, then $f_{1}=p 1 x+q 1 y+r 1$

Rule 2 If $x$ is $A_{2}$ and $y$ is $B_{2}$, then $f_{2}=p 2 x+q 2 y+r 2$

where $\overline{w_{i}}$ is firing strength of the earlier normalized layer and pi qi ri are the resultant attribute sets.

Layer 5 is gross output layer, whose node is marked as $\Sigma$. In this layer we have only one node called fixed node, indicated by a circle, which gives inclusive output by adding up all approaching signals

$Q_{5}, i=$ fout $=\Sigma \bar{w}_{i} \times f_{i}$.

In ANFIS simplified diagram, the first and fourth layers with two adaptive nodes are very crucial. There are two flexible premise attributes [ai, bi] in the first layer which connect two membership functions. In layer 4, we observe three flexible consequent attributes [pi qi ri] belonging to a single-order polynomial. Figure 7 gives the framework of ANFIS model

To accomplish adaptive neuro-fuzzy inference system model for prediction of MRR and SR, the following points are taken into consideration:

1. Initial training data is defined.

2. Attributes for input and output membership function are set.

3. Membership function structure is defined.

4. ANFIS model is trained to extract data.

5. Testing data is defined.

6. ANFIS model is tested.

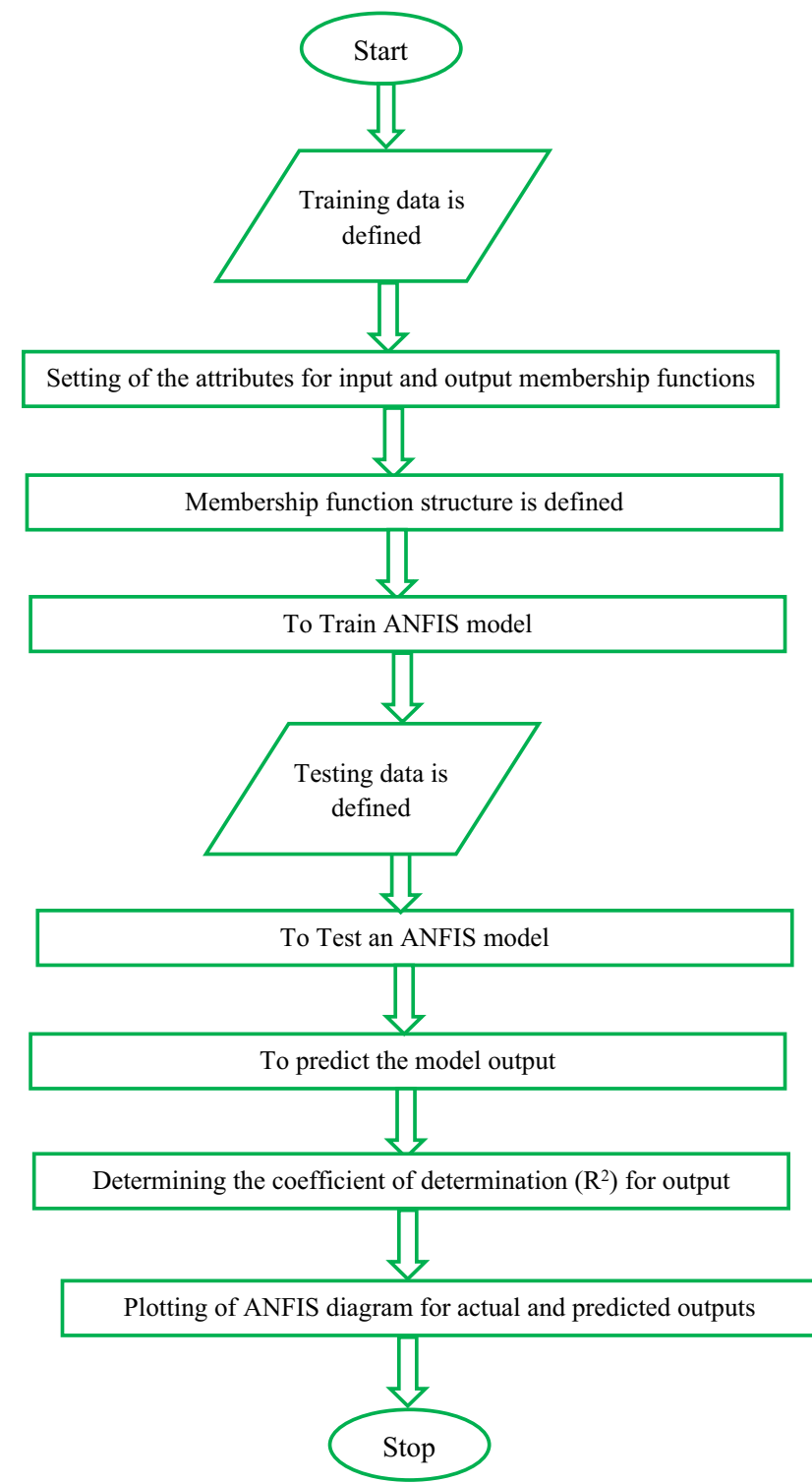

Fig. 7 Framework of the ANFIS model 


\section{Experimental details}

In this study, all experiments were conducted on a Computer Numerical Control (CNC) WEDM ("Ezeecut plus" manufactured by Ratnapar-khi Electronics) as shown in Fig. 8. A molybdenum wire of $0.18 \mathrm{~mm}$ diameter was used as wire electrode material as it is more advantageous in terms of greater melting point and larger tensile strength, which is very helpful during machining of intricate shapes, especially in aerospace and missile components compared with other wire materials. During this process, the diameter of the wire and the pressure of de ionized water as dielectric fluid $\left(2.6 \mathrm{~kg} / \mathrm{cm}^{2}\right)$ were kept constant.

Table 2 demonstrates the four processing input attributes used for ANFIS modelling for training and testing.

\subsection{Measurement of MRR and SR}

The performance of WEDM machine depends mainly on MRR and SR [49]

$\operatorname{MRR}\left(\mathrm{mm}^{3} / \mathrm{min}\right)=\frac{\text { volume of material removed }}{\text { machining time }}$

volume of material removed = length of cut $(\mathrm{mm}) \times$ width of cut $(\mathrm{mm}) \times$ thickness of the sample, where width of cut $(\mathrm{mm})=2 \times$ clearance + diameter of the wire.

Machining time is obtained by means of stop watch for each trial if time is measured with a stop watch. Surface roughness is measured using surface roughness tester (Taylor Hobson, Sutronic-3+) expressed in micrometres. Surface roughness is measured at three distinct areas of
Table 2 Input attributes used in training and testing

\begin{tabular}{llc}
\hline S. no. & Parameters & Values \\
\hline 1 & Pulse on time $\left(T_{\text {on }}(\mu \mathrm{s})\right.$ & $30-50$ \\
2 & Pulse off time $\left(T_{\text {off }}\right)(\mu \mathrm{s})$ & $10-14$ \\
3 & Peak current $(\mathrm{I})(\mathrm{A})$ & $2-4$ \\
4 & Voltage $(\mathrm{V})(\mathrm{V})$ & $40-50$ \\
\hline
\end{tabular}

the work surface and the average value of surface roughness is then calculated. Table 3 shows the experimental design for WEDM of Nitinol alloy developed by response surface methodology (RSM) face-centred central composite design (CCD).

\section{Data analysis: prediction-modelling for material removal rate and SR using artificial neural networks and adaptive neuro-fuzzy inference system}

\subsection{Artificial neural network modelling}

Neural network modelling is commonly adopted soft computing technique to solve intricate nonlinear problems. The neural network constitutes extensive interrelated neural computing elements. In this research article, MATLAB software was employed for designing ANN architecture. The input layer related to $T_{\text {on }}, T_{\text {off }} I_{\text {peak }}$ and Gap voltage whereas the output layer related to material removal rate or surface roughness. In this model, the input layer is interrelated with a hidden layer of neuron
Fig. 8 Schematic diagram of WEDM process of a Nitinol alloy

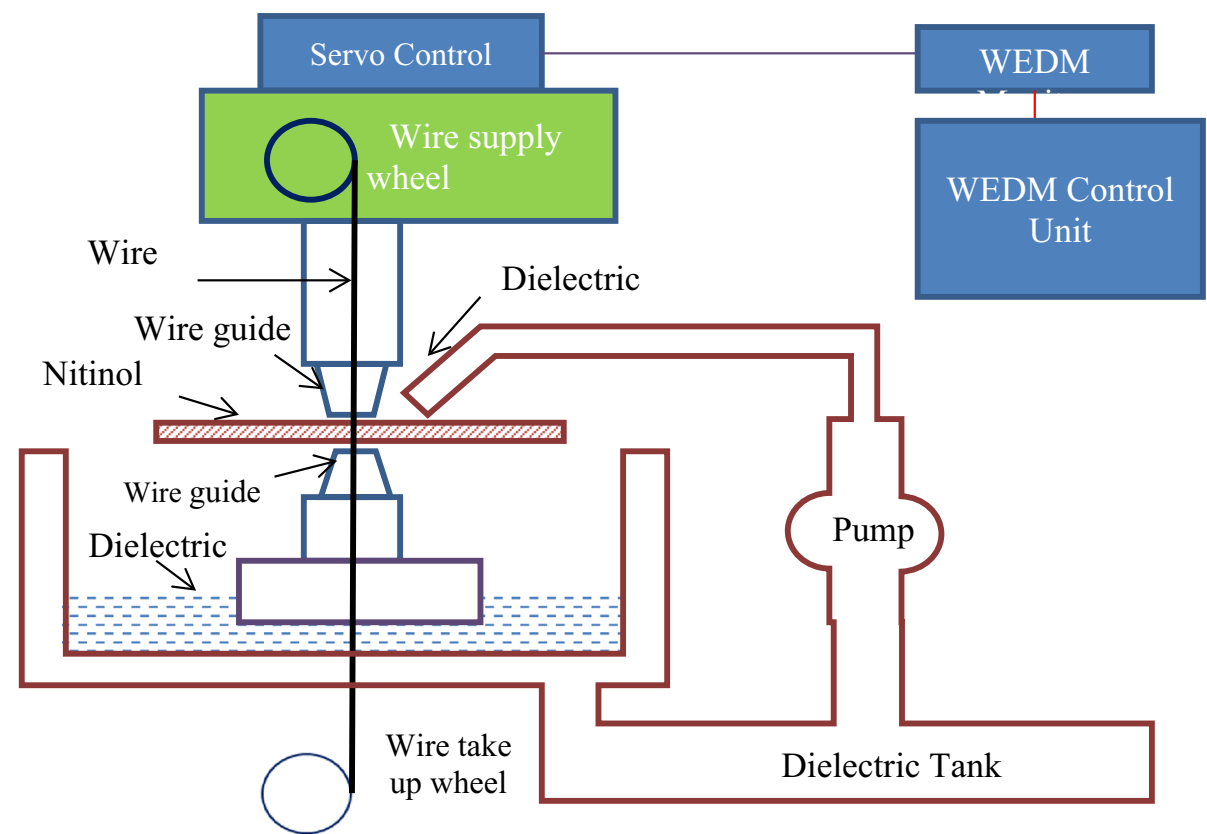


Table 3 Experimental matrix design and their results

\begin{tabular}{|c|c|c|c|c|c|c|}
\hline S. no. & $\begin{array}{l}\text { Pulse on time } \\
\left(T_{\text {on }}\right)(\mu \mathrm{s})\end{array}$ & $\begin{array}{l}\text { Pulse off time } \\
\left(T_{\text {off }}\right)(\mu \mathrm{s})\end{array}$ & $\begin{array}{l}\text { Peak cur- } \\
\text { rent (I) (A) }\end{array}$ & Voltage (V) & $\operatorname{MRR}\left(\mathrm{mm}^{3} / \mathrm{min}\right)$ & $\begin{array}{l}\text { Surface } \\
\text { roughness } \\
(\mu \mathrm{m})\end{array}$ \\
\hline 1 & 50 & 14 & 4 & 50 & 2.768 & 2.52 \\
\hline 2 & 50 & 14 & 4 & 40 & 2.793 & 2.54 \\
\hline 3 & 50 & 14 & 2 & 40 & 2.745 & 1.6 \\
\hline 4 & 30 & 10 & 2 & 50 & 3.542 & 1.91 \\
\hline 5 & 50 & 14 & 2 & 50 & 2.881 & 1.58 \\
\hline 6 & 40 & 12 & 3 & 50 & 2.845 & 2.4 \\
\hline 7 & 40 & 12 & 3 & 45 & 2.854 & 2.44 \\
\hline 8 & 30 & 14 & 4 & 40 & 3.131 & 2.72 \\
\hline 9 & 30 & 10 & 4 & 40 & 3.634 & 2.75 \\
\hline 10 & 50 & 12 & 3 & 45 & 2.785 & 2.23 \\
\hline 11 & 40 & 14 & 3 & 45 & 2.74 & 2.32 \\
\hline 12 & 40 & 10 & 3 & 45 & 2.761 & 2.42 \\
\hline 13 & 40 & 12 & 3 & 45 & 2.728 & 2.44 \\
\hline 14 & 30 & 12 & 3 & 45 & 2.978 & 2.45 \\
\hline 15 & 40 & 12 & 3 & 45 & 2.926 & 2.54 \\
\hline 16 & 50 & 10 & 4 & 40 & 2.756 & 2.45 \\
\hline 17 & 40 & 12 & 3 & 45 & 3.283 & 1.76 \\
\hline 18 & 40 & 12 & 4 & 45 & 2.607 & 1.68 \\
\hline 19 & 30 & 10 & 4 & 50 & 2.845 & 2.44 \\
\hline 20 & 30 & 10 & 2 & 40 & 3.652 & 1.88 \\
\hline 21 & 40 & 12 & 3 & 45 & 2.26 & 2.64 \\
\hline 22 & 40 & 12 & 3 & 45 & 2.927 & 2.46 \\
\hline 23 & 40 & 12 & 2 & 45 & 2.92 & 2.68 \\
\hline 24 & 50 & 10 & 2 & 50 & 3.56 & 2.73 \\
\hline 25 & 40 & 12 & 3 & 40 & 3.425 & 1.98 \\
\hline 26 & 30 & 14 & 2 & 40 & 2.875 & 2.44 \\
\hline 27 & 30 & 14 & 2 & 50 & 3.754 & 1.85 \\
\hline 28 & 50 & 10 & 2 & 40 & 2.529 & 1.74 \\
\hline 29 & 50 & 10 & 4 & 50 & 2.26 & 2.62 \\
\hline 30 & 30 & 14 & 4 & 50 & 3.014 & 2.71 \\
\hline
\end{tabular}

and the hidden layer is related to output layers. After thorough trials and from operating the network, ANN models for material removal rate and the surface roughness were developed.

ANN model, back-propagation with three different learning algorithms Levenberg-Marquardt (LM), Elman regression neural network and generalized regression neural network (GRNN) were used for predicting WEDM attributes. The most suitable algorithm and neuron number in the hidden layer was found to be Levenberg-Marquardt (LM) with 10 neurons for ANN models. The attributes chosen for predicting ANN model for MRR and SR are shown in Table 4. For swift and superintended learning, Levenberg-Marquardt back-propagation neural network algorithm was used throughout the time of training the network [50-52]. The accomplishment of the network is
Table 4 Selected ANN attributes for MRR and SR

\begin{tabular}{ll}
\hline Network parameters & Values \\
\hline Network structure & $4-10-1$ \\
Total number of training/testing data sets & $70 / 30$ \\
Network algorithm & Feed forward back- \\
& propagation \\
& (FFBP) \\
Type of transfer function & TRANSIG \\
Type of training function & TRAINLM \\
Learning function & LEARNGDM \\
Performance function & MSE \\
\hline
\end{tabular}

expressed in terms of mean square error (MSE) and average percentage error (APE). MSE can be calculated as: 
MSE $=\frac{1}{x \times y} \sum_{i=1}^{X} \sum_{j=1}^{Y}\left(p_{j}-q_{j}\right)$

where $X$ is the number of output nodes, $Y$ is the total number of training data, $p_{j}$ is output of $j$ th neuron and $q_{j}$ is the predicted value of jth neuron [53]. In the current neural network model for MRR and surface roughness throughout simulation, the correlation coefficient $(R)$ values obtained for MRR and surface roughness are 0.9815 and 0.9878 as represented in Figs. 9 and 10. From statistical perspective, a network can accurately compare the input attributes with output attributes. If the correlation of coefficients is close to 1 , which exhibits the collation of experimental and anticipated values of MRR and surface roughness by feed forward back-propagation neural network (FFBP).

\subsection{ANFIS modelling}

In this section, an ANFIS model with three different membership functions (gauss $\mathrm{mf}$, gauss $2 \mathrm{mf}, \mathrm{g}$ bell $\mathrm{mf}$ ) were employed for anticipating both MRR and SR during WEDM of Nitinol alloy using MATLAB. The entire experimental data set was split into training and testing datasets. Graphical user interface (GUI) was generally adopted for training and testing ANFIS model. The training data sets include 70 observations whereas testing includes 30 observations. Testing 30 data sets was considered for predicting WEDM responses.

The parameters chosen for predicting and developing ANFIS model are illustrated in Table 5. Two Gaussian-type membership functions (gauss $\mathrm{mf}$ ) have been preferred for input variables while constant-type membership function (MF) has been used for MRR and SR as shown in Fig. 11. Grid partition method is generally applied for generating an fuzzy inference system (FIS) when we test for fewer data sets. During training of ANFIS, least squares combined with back-propagation were applied
Fig. 9 Regression analysis between the actual and predicted values by FFBP-neural network of a Nitinol alloy for training, testing, validation, and overall for MRR
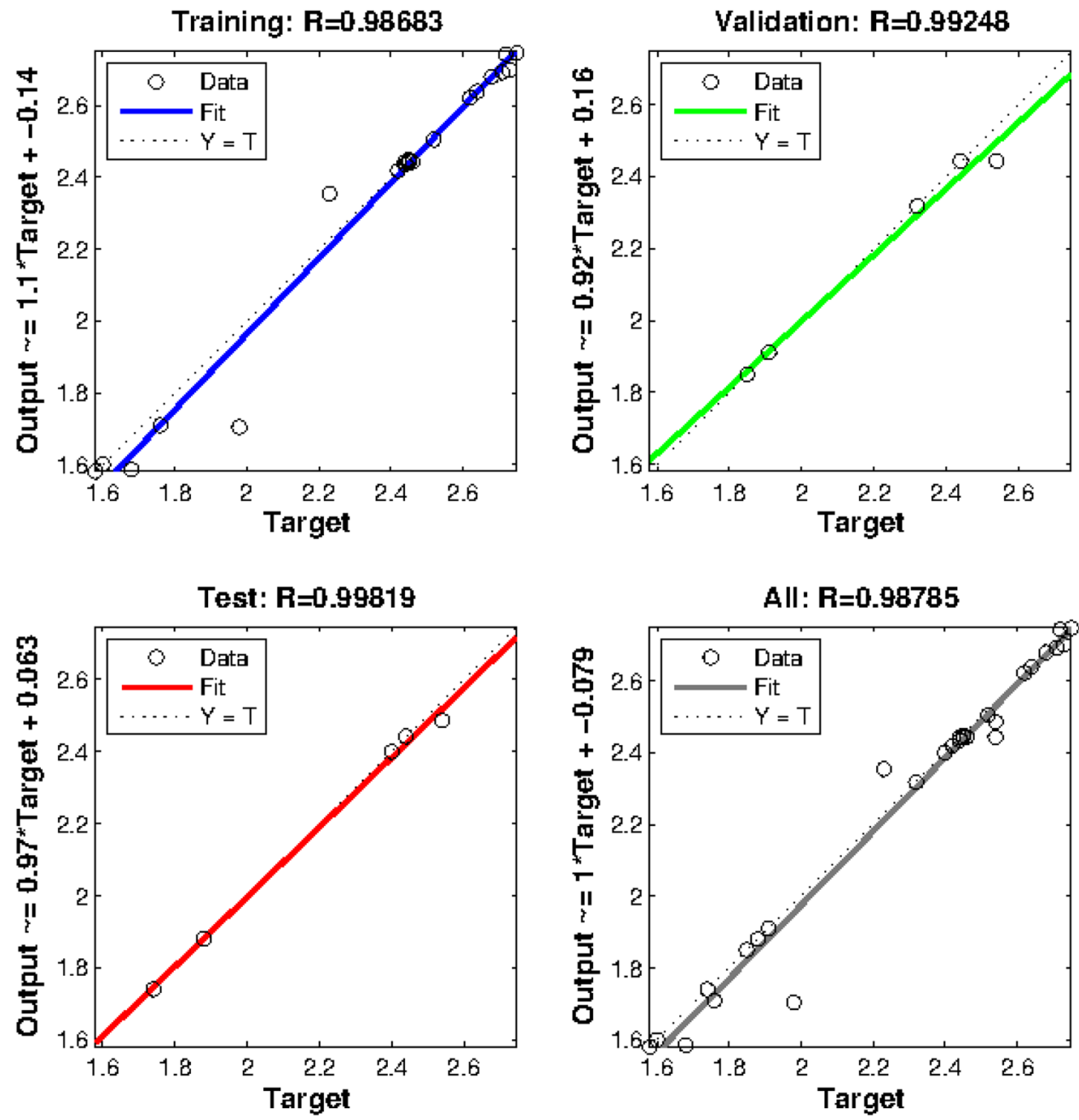
Fig. 10 Regression analysis between the actual and predicted values by FFBP-neural network of a Nitinol alloy for training, testing, validation, and overall for SR
Training: $\mathbf{R}=\mathbf{0} .97863$

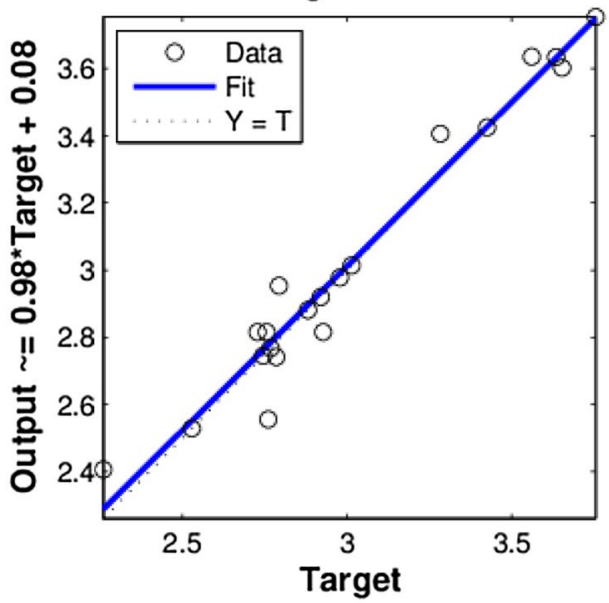

Test: $\mathbf{R}=\mathbf{0} .98987$

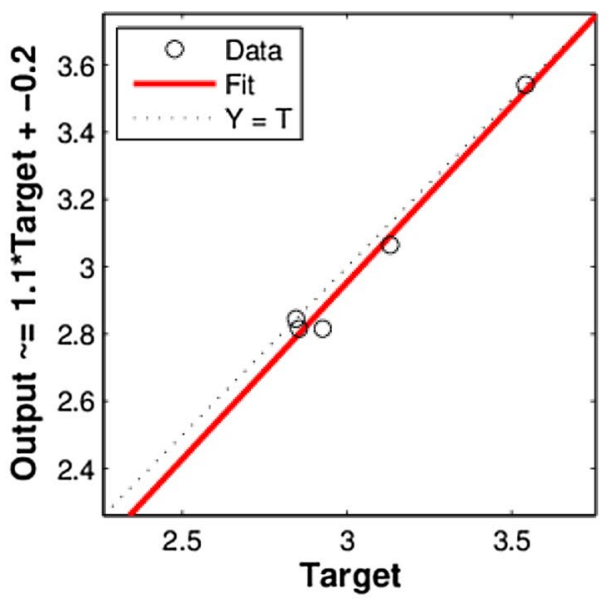

Validation: $\mathbf{R}=0.99522$

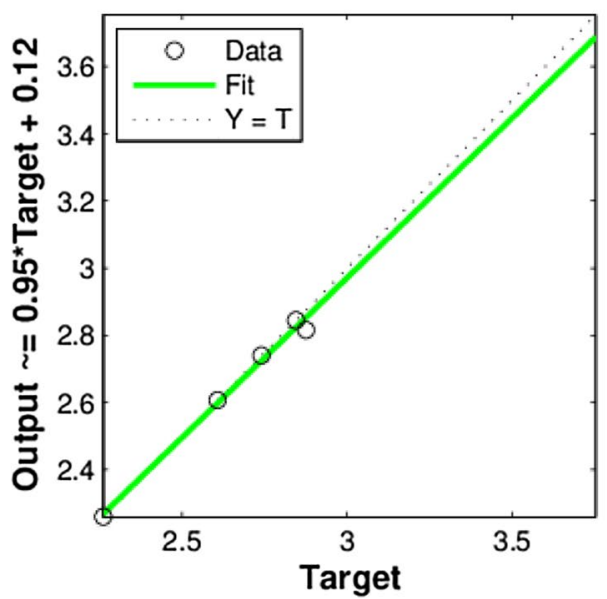

All: $\mathbf{R}=\mathbf{0 . 9 8 1 5 1}$

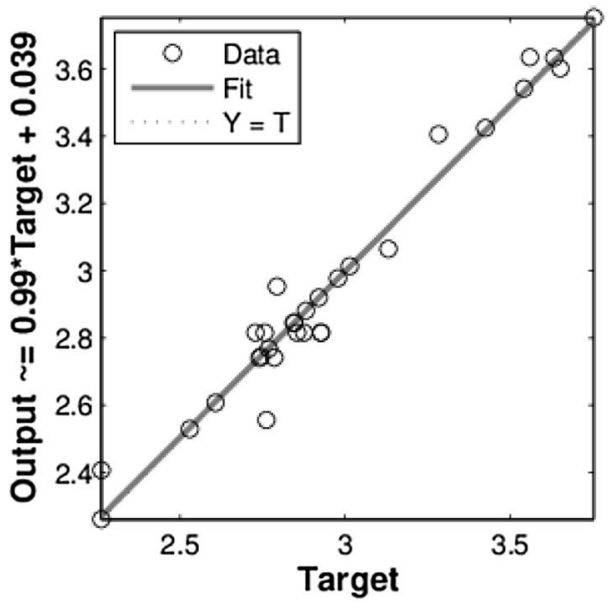

Table 5 Selected ANFIS attributes for training of ANFIS model for MRR and SR

\begin{tabular}{ll}
\hline ANFIS attributes & Values \\
\hline Total number of inputs & 04 \\
Total number of outputs & 02 \\
Total number of training/testing data sets & $70 / 30$ \\
Type of input membership function & Gauss \\
Type of output membership function & Constant \\
Optimization method adopted & hybrid \\
Error tolerance & 0 \\
Total number of fuzzy rules & $8 /$ output \\
Number of epochs & 500/output \\
\hline
\end{tabular}

for better trained optimized FIS. It includes $T_{\text {on }}, T_{\text {off }} I_{\text {peak }}$ $V$ and MRR, SR. The deviation of actual and predicted data sets is illustrated in Fig. 12. The blue dots represent experimental output data and pink dots represent ANFIS anticipated data. The conspiracy shows distribution of data is unity in nature. Figure 13 gives the gauss initial membership functions of one of the input attribute (i.e. 222 1) with respect to SR, and Fig. 14 gives the FIS rule Sugeno-type architecture when Gaussian membership is mixed with constant function. Grid partition method is generally adopted in ANFIS model structure for both MRR and SR as illustrated in Fig. 15. The effect of each individual input attributes on WEDM responses is indicated by 3D contour plots as represented in Figs. 16 and 17. ANFIS architecture with four input attributes and one output with 2221 gauss membership function, we get 8 fuzzy rules as illustrated in Fig. 18. The variation of ANFIS-predicted WEDM response attributes with actual experimental attributes in the form of error and accuracy percentages is given in Table 6 . Correlation coefficient is a statistical process for determining the relation between the testing input data sets and the predicted WEDM output attributes. 

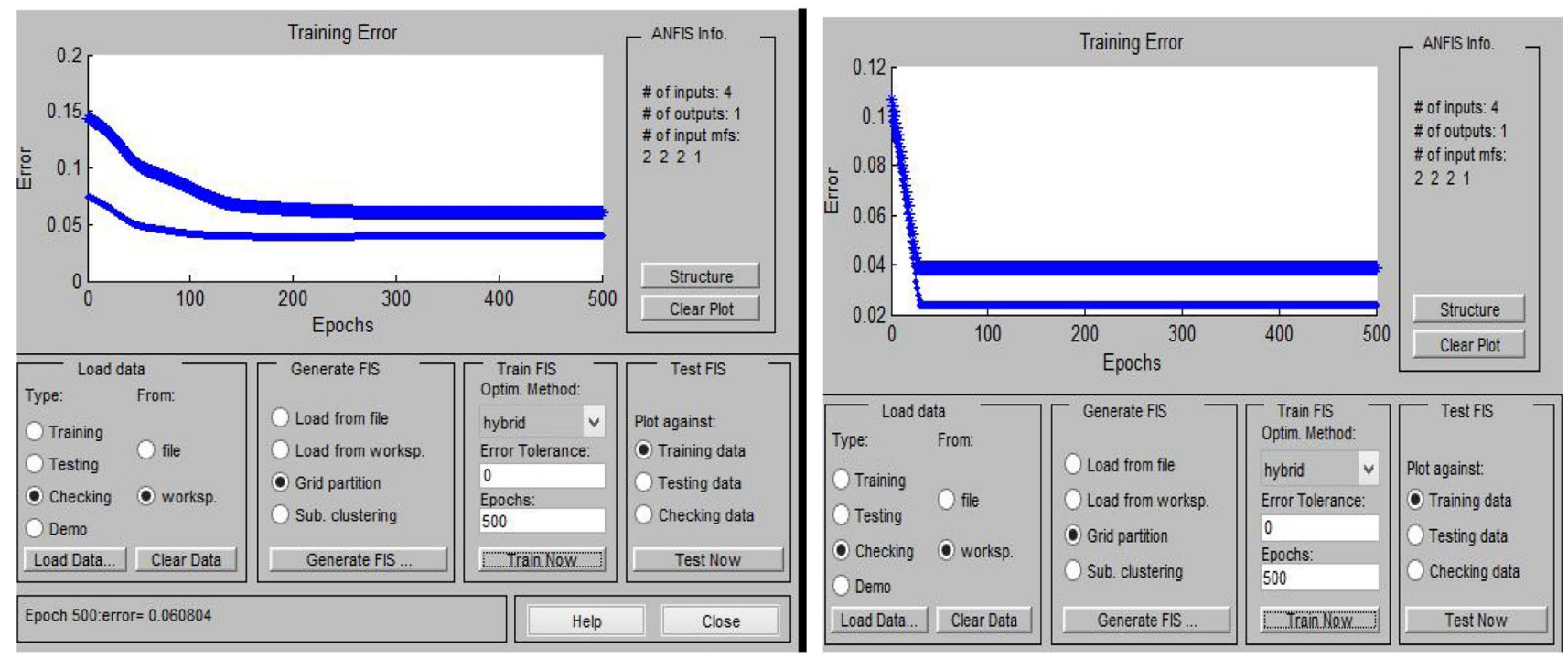

Fig. 11 The training of data for both MRR and SR
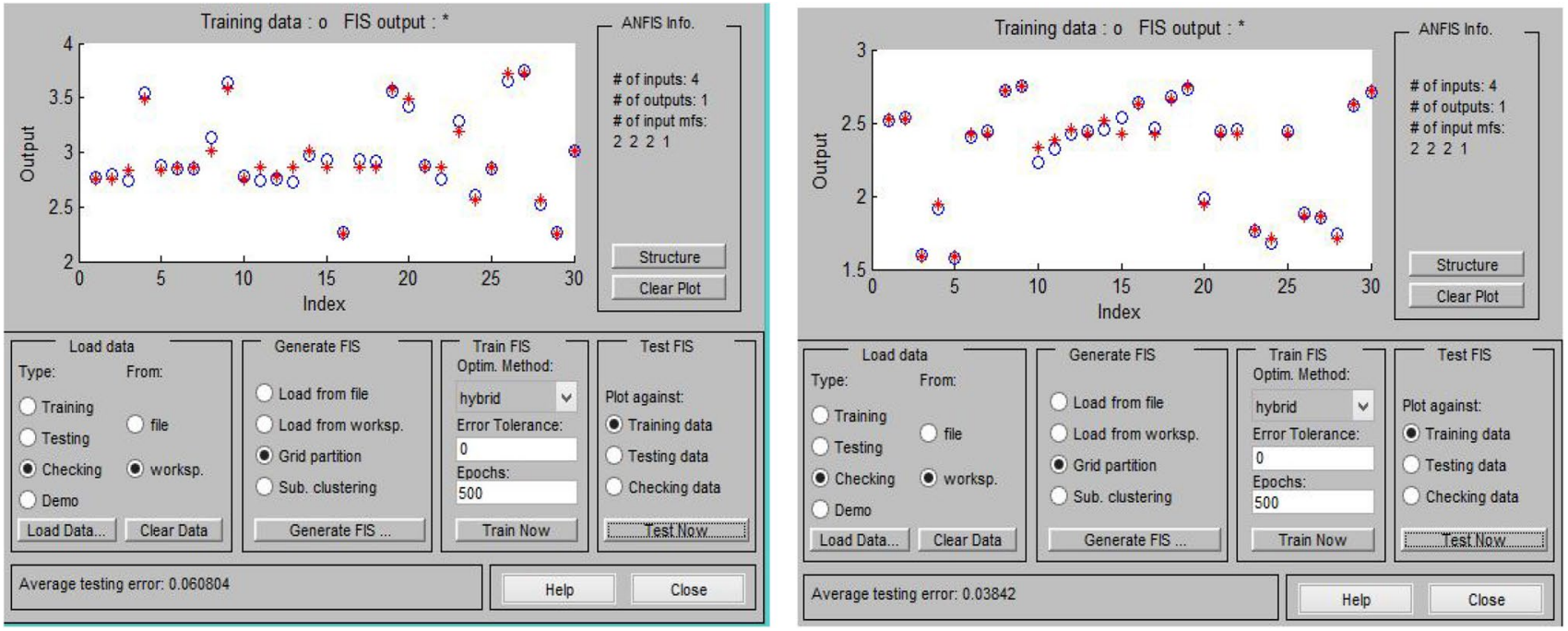

Fig. 12 Distribution of experimental and predicted data of MRR and SR (testing)

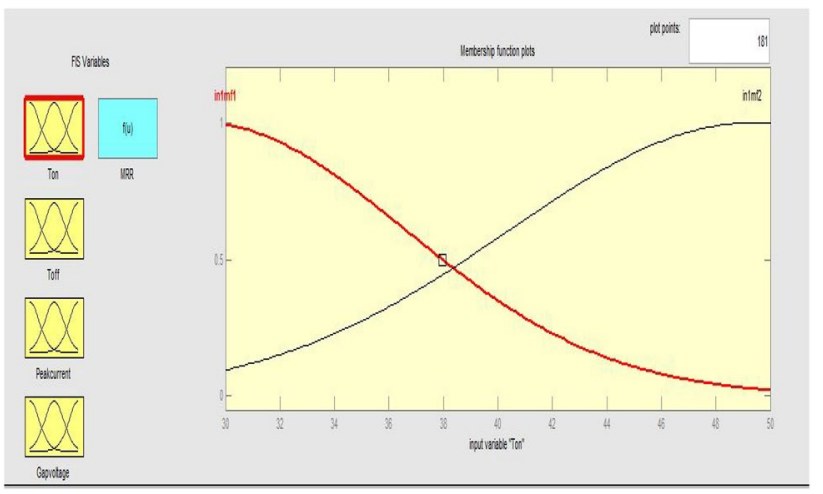

Fig. 13 Membership function for pulse on time $\left(T_{\text {on }}\right)$ on SR

\section{Results and discussion}

ANN models, back-propagation with three different algorithms Levenberg-Marquardt (LM), Elman regression neural network and generalized regression neural network (GRNN) were used for anticipating the WEDM responses. The statistical measures like MSE, RMSE, MAE and standard deviation of all three neural networks are illustrated in Table 7. LM back-propagation algorithm with 10 neurons gives fewer statistical errors and is more accurate than Elman RNN and GRNN. ANFIS models with three different membership functions (gauss MF,

\section{SN Applied Sciences}




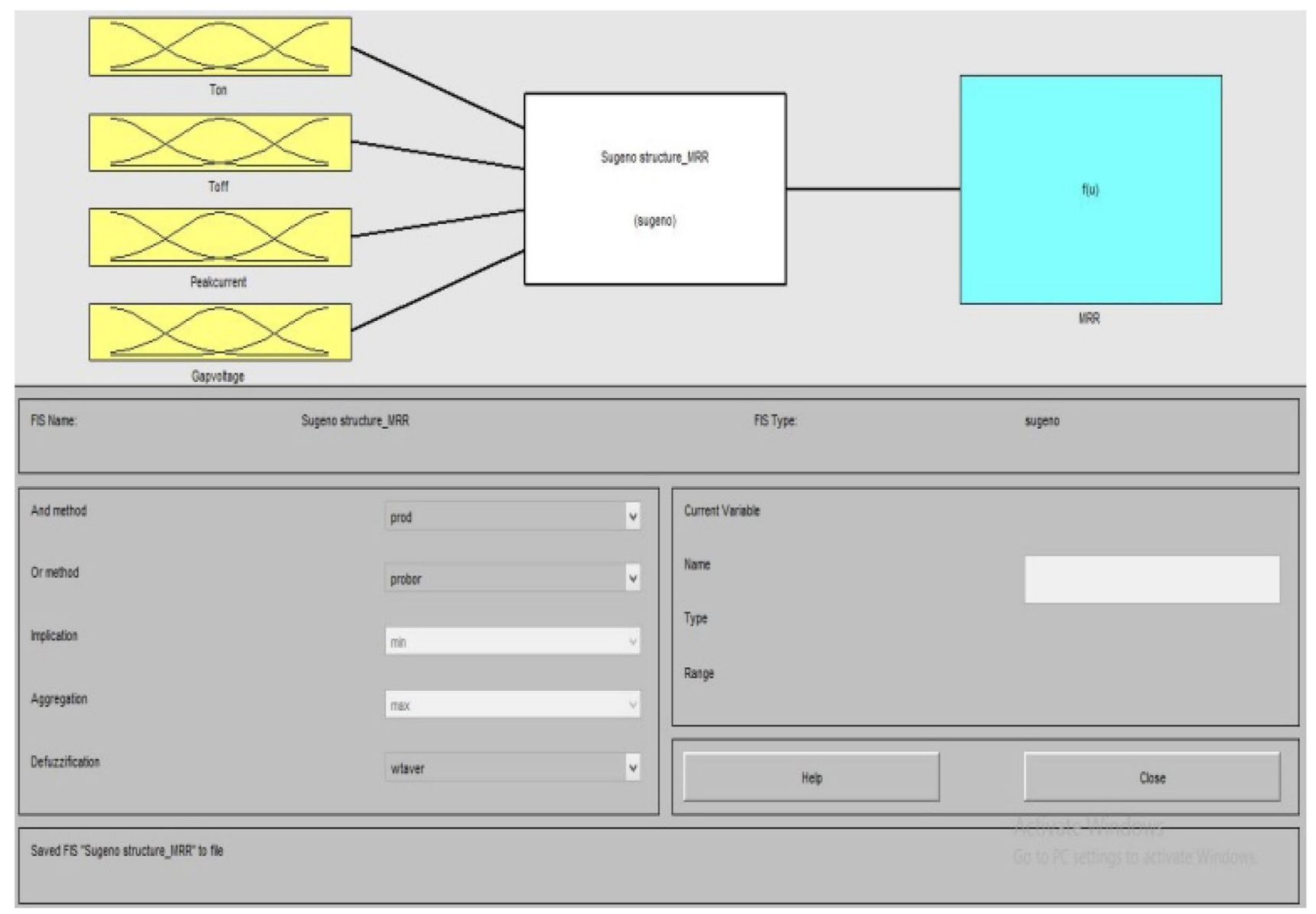

Fig. 14 Sugeno-type structure (FIS) for MRR and SR

Fig. 15 ANFIS model structure for MRR and SR

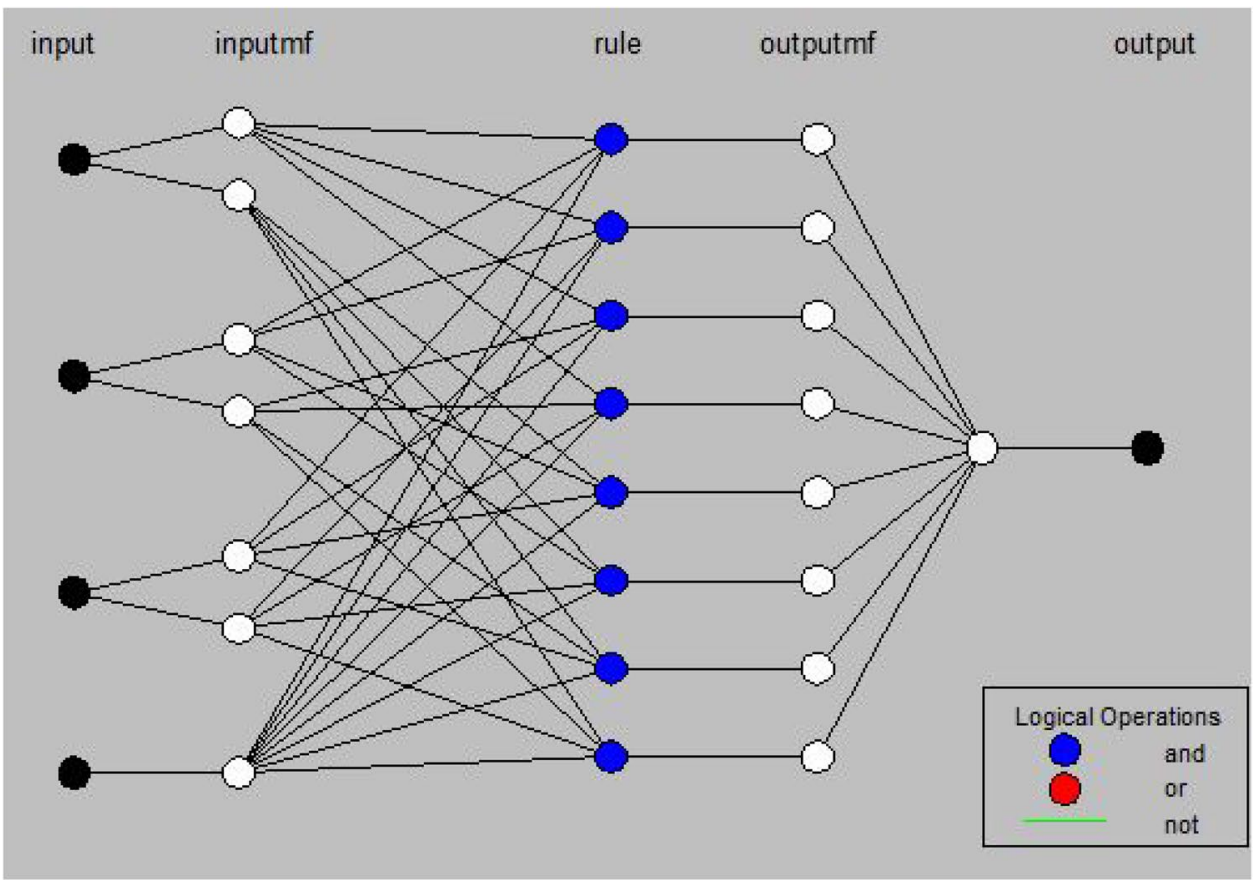

SN Applied Sciences

a SPRINGER NATURE journal 

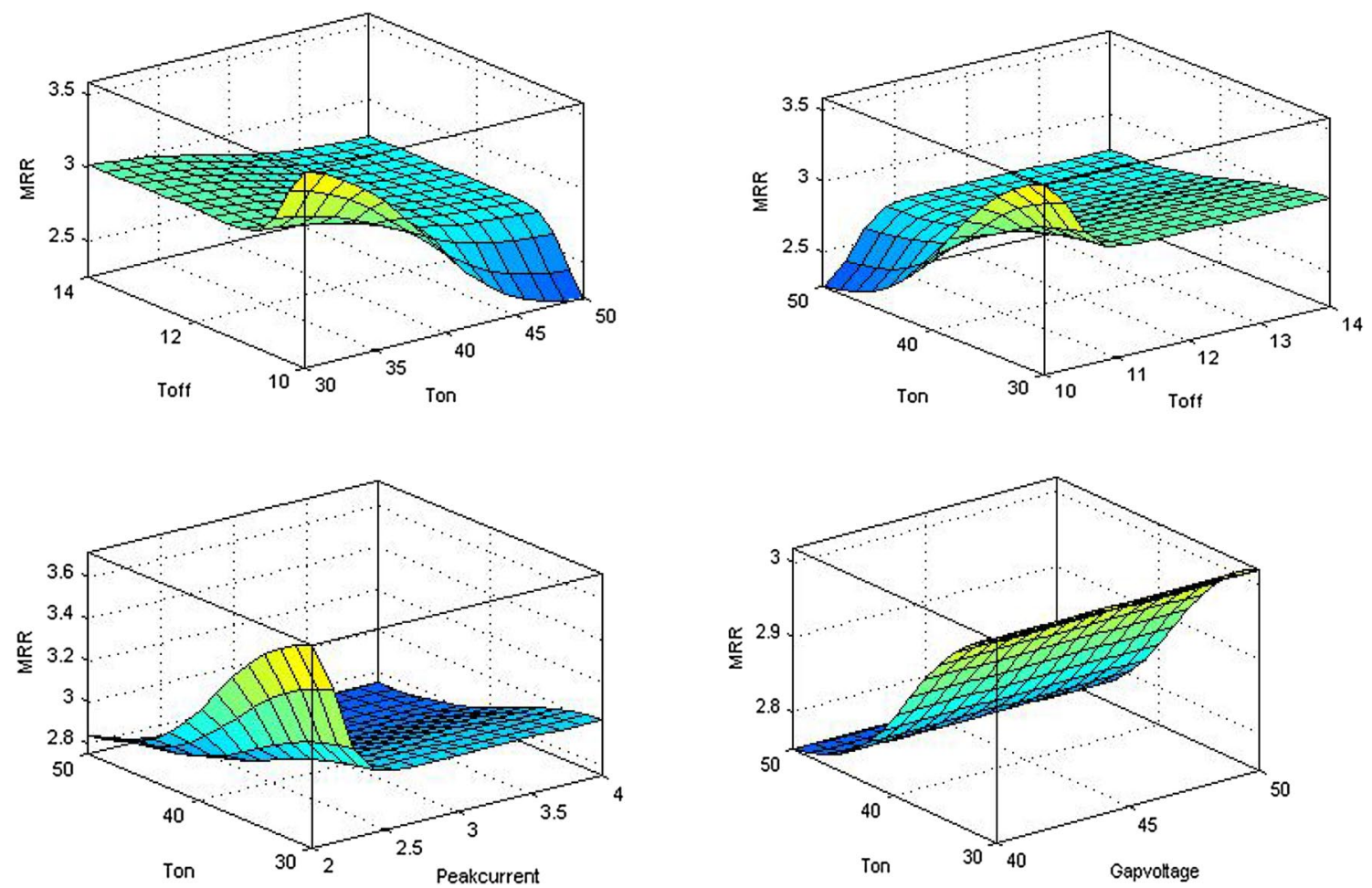

Fig. 16 Exhibits surface contour plot of predicting MRR

gauss2MF, gbell MF) were trained and tested for predicting WEDM responses. Statistical errors were fewer compared to the remaining two MF for the same input variables as shown in Table 8. As per the statistical perspective ANFIS model will give more accuracy than ANN models. This exhibits variation of experimental responses with the predicted responses being a validation of both ANN and adaptive neuro-FIS model. Both may then be utilized to predict the MRR and surface roughness.

The absolute percentage error $\left(E_{i}\right)$, mean absolute percentage error $\left(E_{\mathrm{av}}\right)$, root mean square error (RMSE) of both MRR and SR are calculated by Eqs. (12)-(14)

$E_{i}=\frac{\text { |actual output value }- \text { predicted ANFIS output value } \mid}{\text { actual output value }} \times 100$

$E_{\mathrm{avg}}=\frac{1}{M} \sum_{i=1}^{M} E_{i}$

where $E_{i}$ is the \% error of the data set $i ; E_{\text {avg }}$ is the average percentage error; $M$ is the number of datasets

$\mathrm{RMSE}=\sqrt{\frac{1}{M}} \sum_{l=1}^{M}\left(x_{i}-y_{i}\right)^{2}$ where $M$ is the number of testing datasets, $x_{i}$ is the experimental value and $y_{i}$ is the value, anticipated by artificial neural networks and adaptive neuro-FIS model.

Figures 19 and 20 show the coefficient of determination of ANN model $\left(R^{2}\right)$ for MRR, and surface roughness was 0.9491 , i.e. 94.91 and 0.9758 , i.e. 97.58 , respectively, whereas for ANFIS-predicted model $\left(R^{2}\right)$ for MRR and SR it was 0.9667 , i.e. 96.67 and 0.9891 , i.e. 98.91 percentage of the variance. The adjusted $R$-square value for MRR and SR of ANN model is 0.9473 and 0.9749 which is very close to $R$-square which makes our neural networks and adaptive neuro-FIS model more accurate. The root mean square error (RMSE) of MRR and SR of ANN model is 0.088286 and 0.04369 whereas for ANFIS model it is 0.070627 and 0.038525 ; this is used to anticipate the variance between the experimental and predicted value of the model. From Figs. 21 and 22, we observe that output of ANFIS-predicted model for MRR and SR is very close to experimental values compared to ANN anticipated models. The mean absolute error (MAE) obtained from ANFIS-predicted model for MRR and SR is 0.0611 and 0.0285 which is very low compared to ANN MAE, i.e. 0.0652 and 0.04086 . 

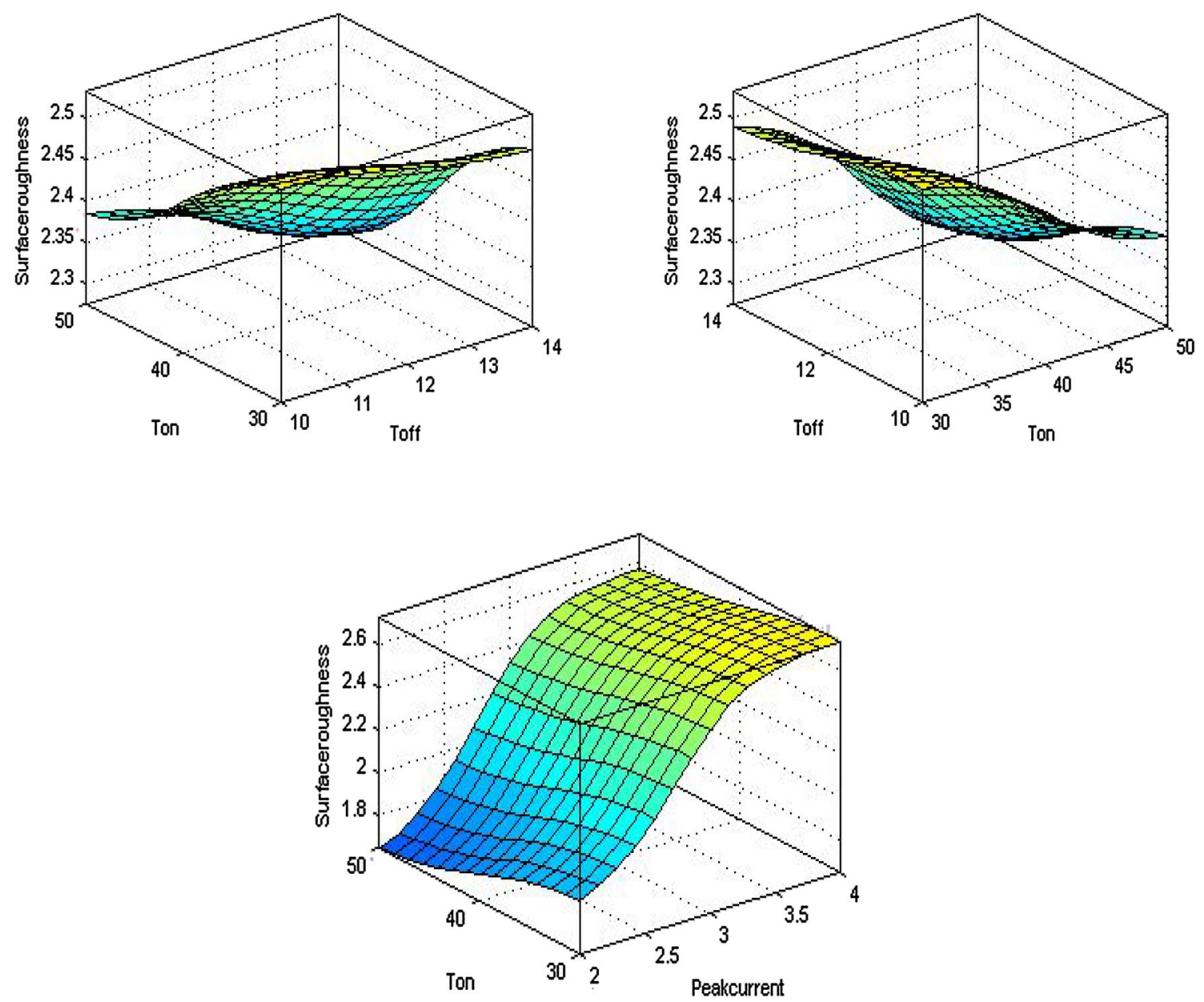

Fig. 17 Exhibits surface contour plot of predicting SR

Fig. 18 A sample set of FIS rules for prediction of MRR and surface roughness

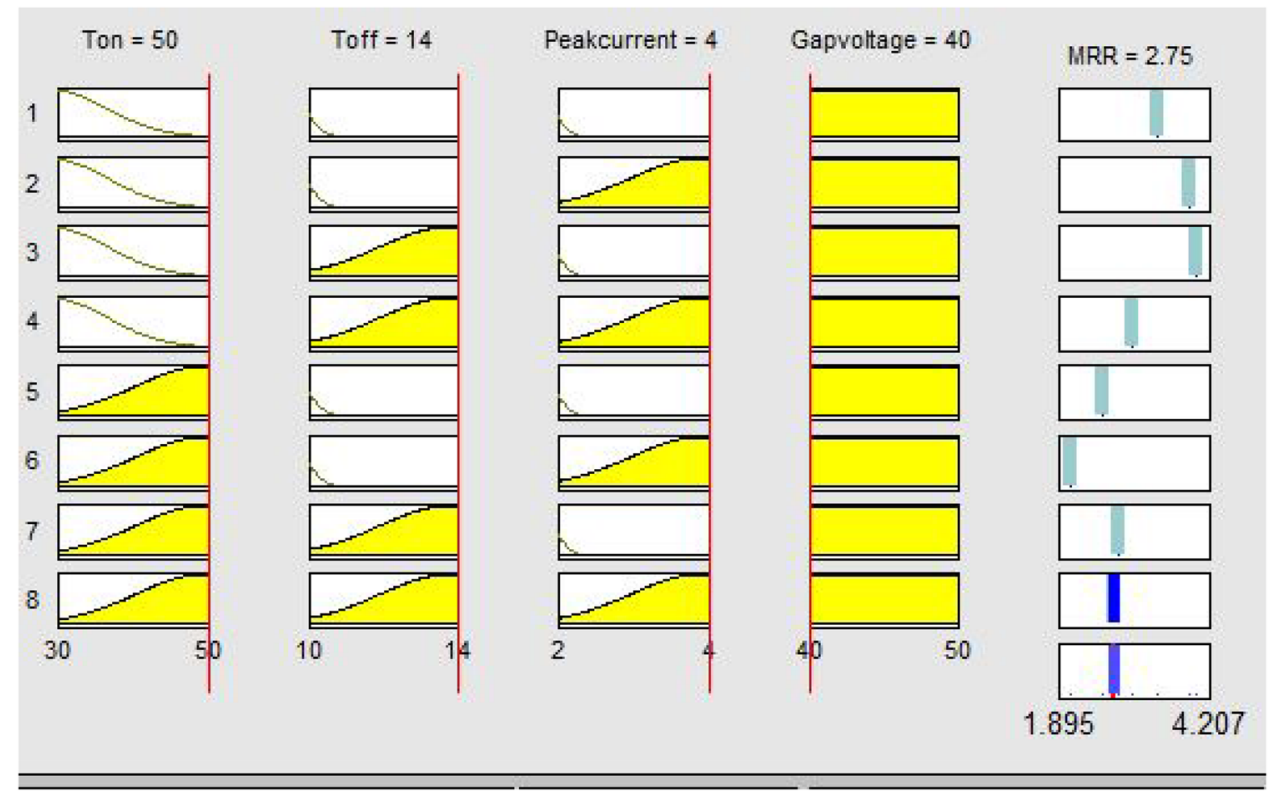

SN Applied Sciences

a SPRINGer Nature journal 


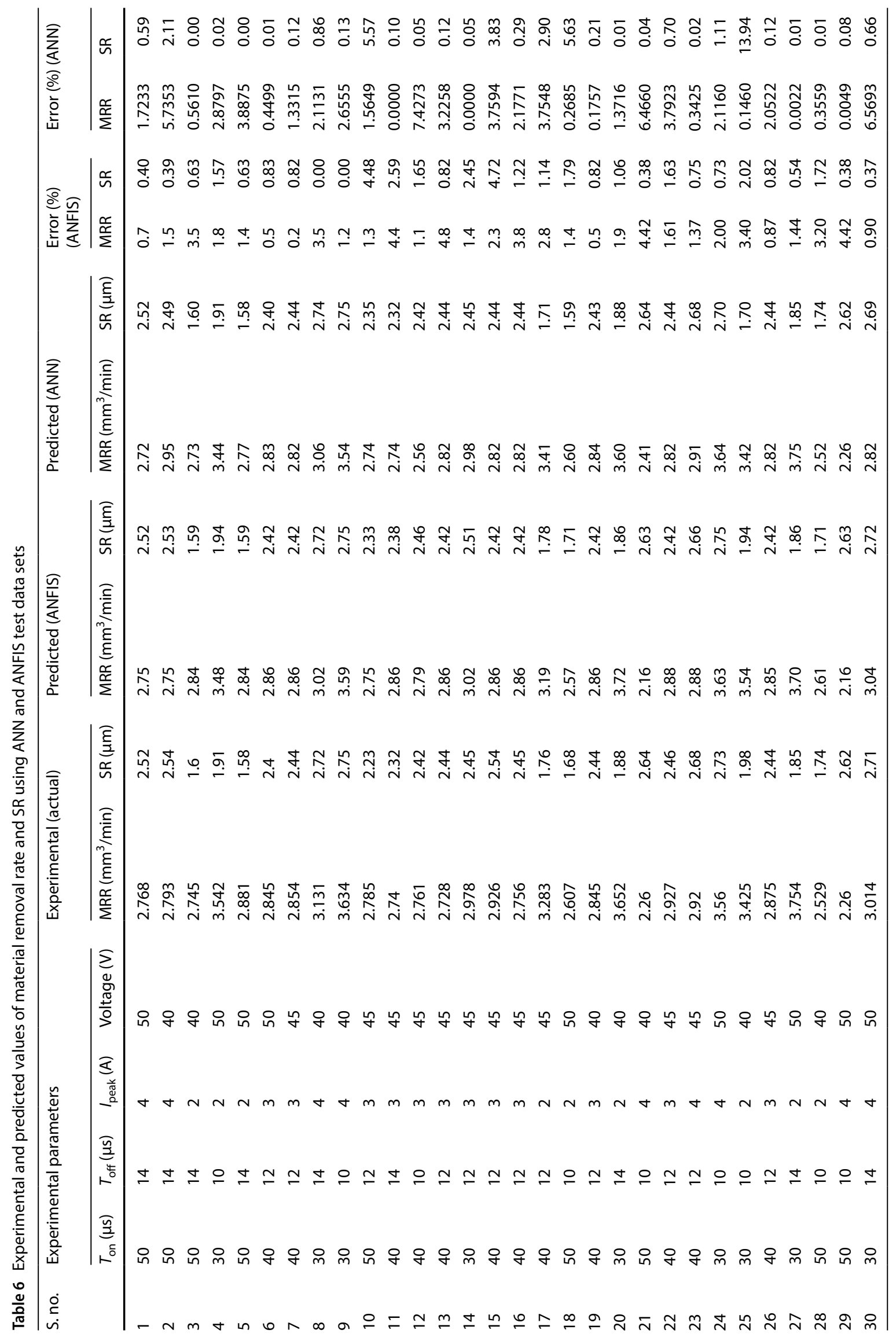


Table 7 Statistical values for WEDM responses of a Nitinol alloy, ANN models

Table 8 Statistical values for WEDM responses of a Nitinol alloy, ANFIS models

\begin{tabular}{llllll}
\hline $\begin{array}{l}\text { WEDM } \\
\text { responses }\end{array}$ & Model & MAE & MSE & RMSE & SD \\
\hline MRR & Generalized regression neural network (GRNN) & 0.1327 & 0.02167 & 0.14723 & 0.3984 \\
& Elman back-propagation neural network & 0.0881 & 0.008160 & 0.09033 & 0.3894 \\
& Levenberg-Marquardt (LM) & 0.0652 & 0.007794 & 0.088286 & 0.3794 \\
SR & Generalized regression neural network (GRNN) & 0.06431 & 0.004792 & 0.06922 & 0.3905 \\
& Elman back-propagation neural network & 0.04199 & 0.001924 & 0.04386 & 0.3789 \\
& Levenberg-Marquardt (LM) & 0.04086 & 0.001909 & 0.04369 & 0.374 \\
\hline
\end{tabular}

\begin{tabular}{llllll}
\hline $\begin{array}{l}\text { WEDM } \\
\text { responses }\end{array}$ & Model & MAE & MSE & RMSE & SD \\
\hline MRR & Gauss membership function & 0.06113 & 0.004988 & 0.070627 & 0.3705 \\
& Gauss 2 membership function & 0.0621 & 0.005022 & 0.070866 & 0.3720 \\
& Gbell membership function & 0.0634 & 0.005048 & 0.07105 & 0.3770 \\
SR & Gauss membership function & 0.0285 & 0.001484 & 0.038525 & 0.3689 \\
& Gauss 2 membership function & 0.03583 & 0.001531 & 0.03912 & 0.3712 \\
& Gbell membership function & 0.0378 & 0.001886 & 0.04342 & 0.3714 \\
\hline
\end{tabular}

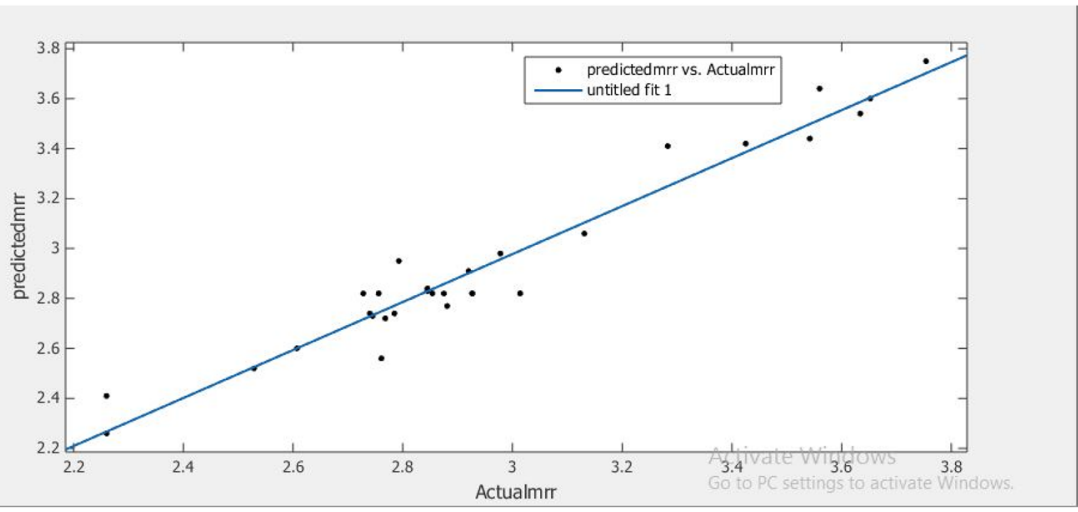

(a)
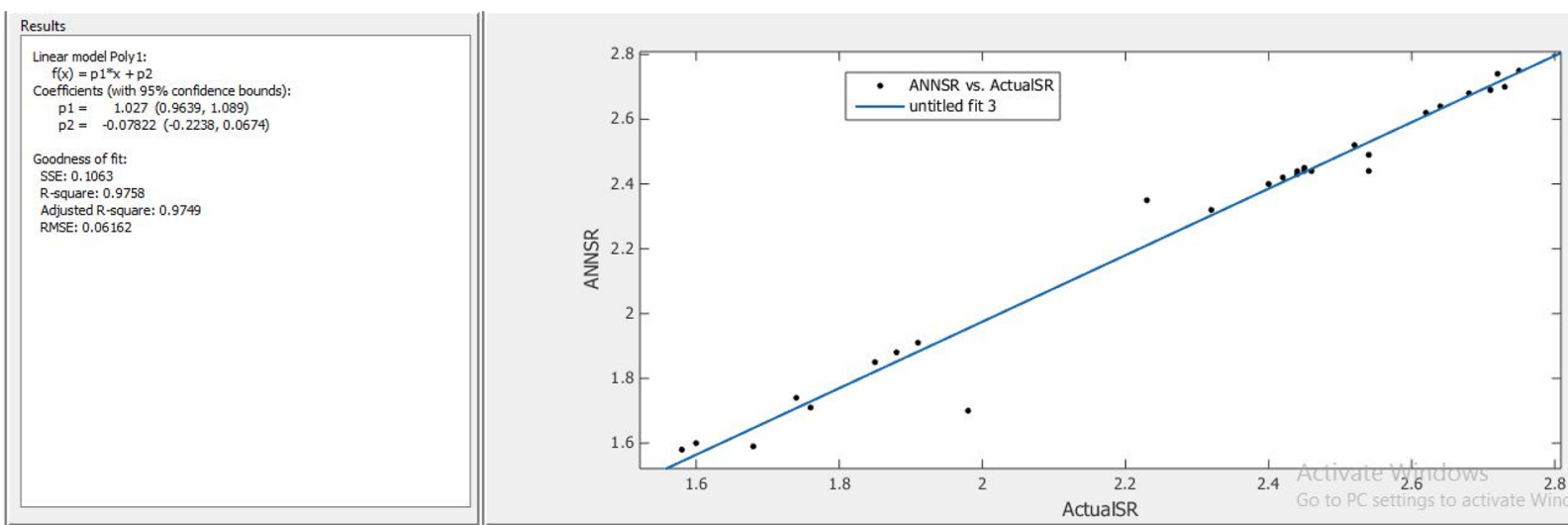

(b)

Fig. 19 Coefficient of determination $\left(R^{2}\right)$ of a Nitinol alloy for ANN model. a MRR, b SR 

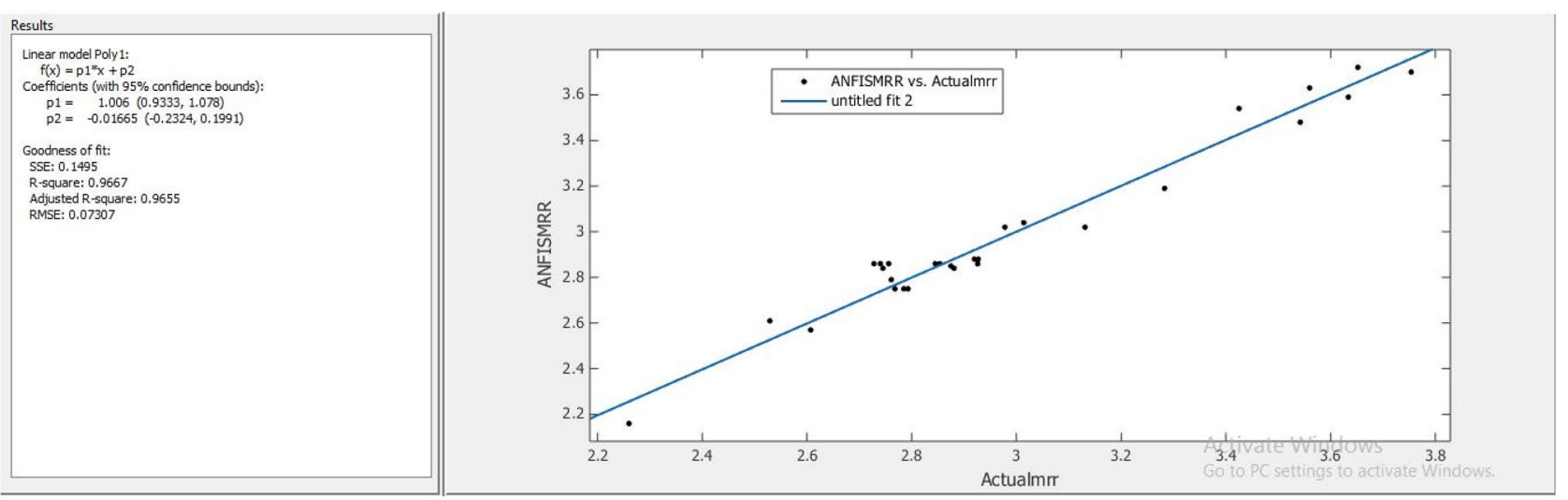

(a)
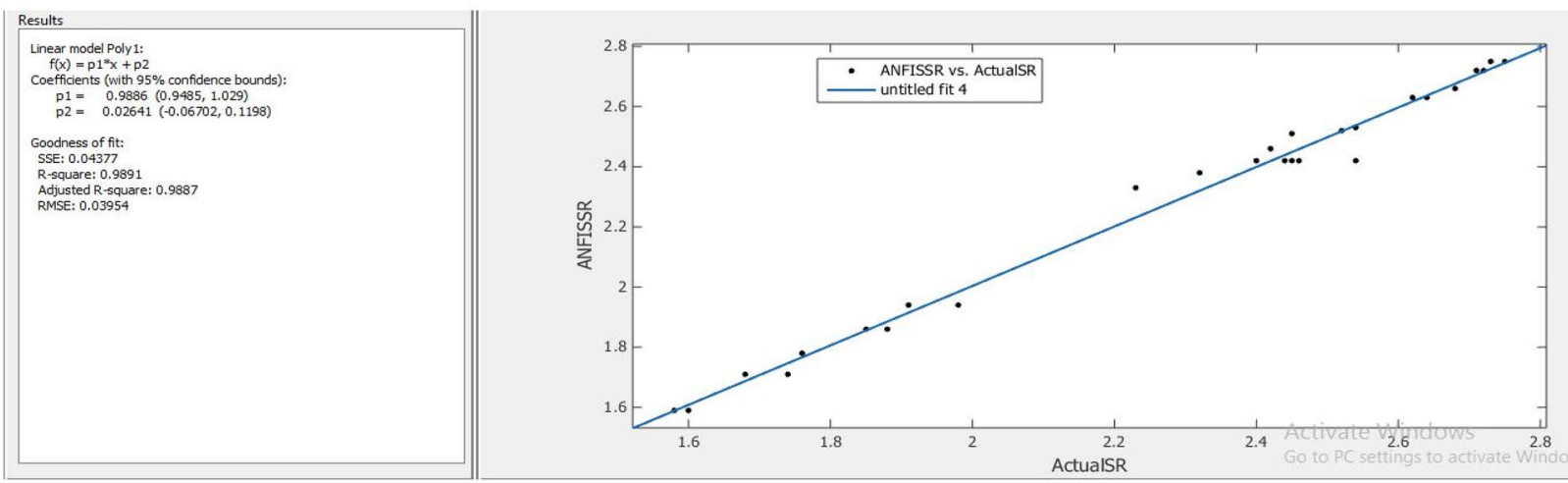

(b)

Fig. 20 Coefficient of determination $\left(R^{2}\right)$ of a Nitinol alloy for ANFIS model, a MRR, b SR

\subsection{Comparison of the artificial neural networks and ANFIS models}

A collation of anticipated values of WEDM output responses of a Nitinol alloy by ANN and ANFIS models is achieved. ANN model, back-propagation with three different algorithms Levenberg-Marquardt (LM), Elman regression neural network (RNN) and generalized regression neural network (GRNN) and ANFIS model were developed using the same input variables. The most suitable algorithm and neuron number in the hidden layer were found as Levenberg-Marquardt (LM) with 10 neurons for ANN models whereas the most suitable membership functions and number of membership functions are found to be gauss and two, respectively. The precision of anticipated models for both artificial neural network and ANFIS was determined by using mean square error (MSE), root mean square error (RMSE), mean absolute percentage error (MAPE), as given in Tables 6 and 7. From these values it may be concluded that the adaptive neuro-FIS model offers more reliable and accurate prediction in combination with artificial neural network models. A comparison of experimental and predicted values of MRR and surface roughness of Nitinol alloy by ANN and ANFIS models is represented in Figs. 23 and 24.

\section{Conclusions}

This article provides insights into the features of both ANN and adaptive neuro-fuzzy inference models for better prediction of output attributes as well as a comparison of both models during WEDM machining of Nitinol alloy. The study is carried initially with the ANN model with three different algorithms and the best algorithm has chosen according to the statistical validation measures. Similarly the ANFIS with three different membership functions and the best has chosen with minimum statistical validation measures. Then, the ANN model will be compared with the ANFIS model and the results obtained will be resumed as follows:

1. Generalized regression neural network is the slowest algorithm in the back-propagation compared with remaining two neural networks (LM and Elman RNN). 


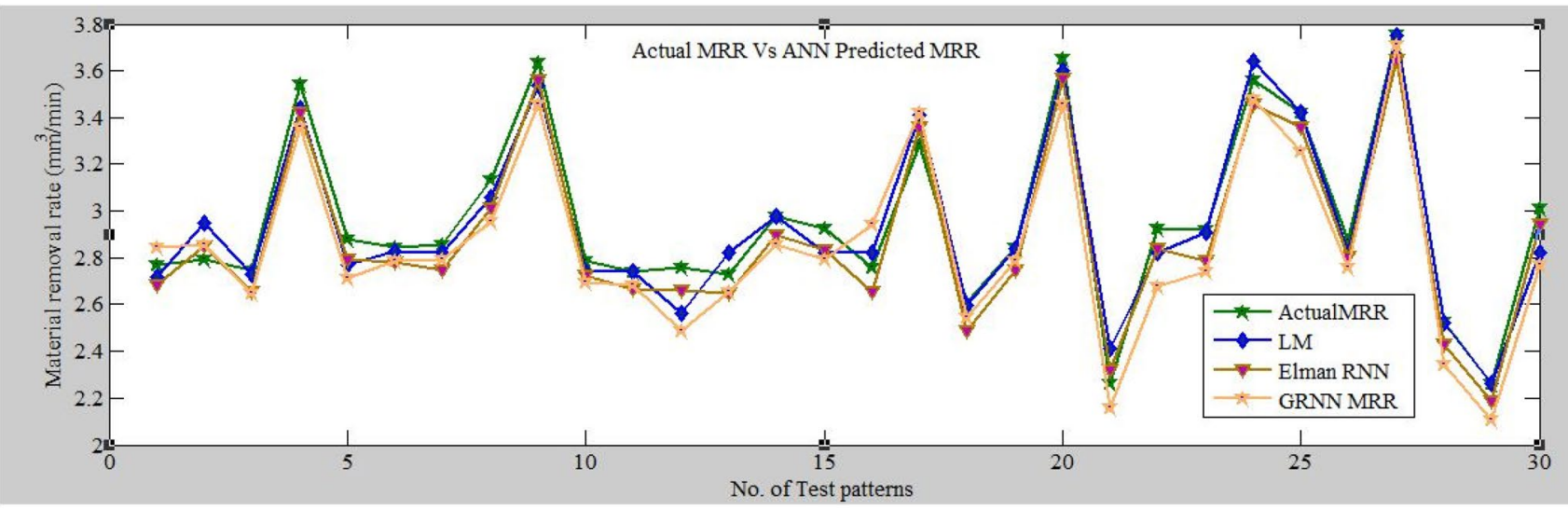

(a)

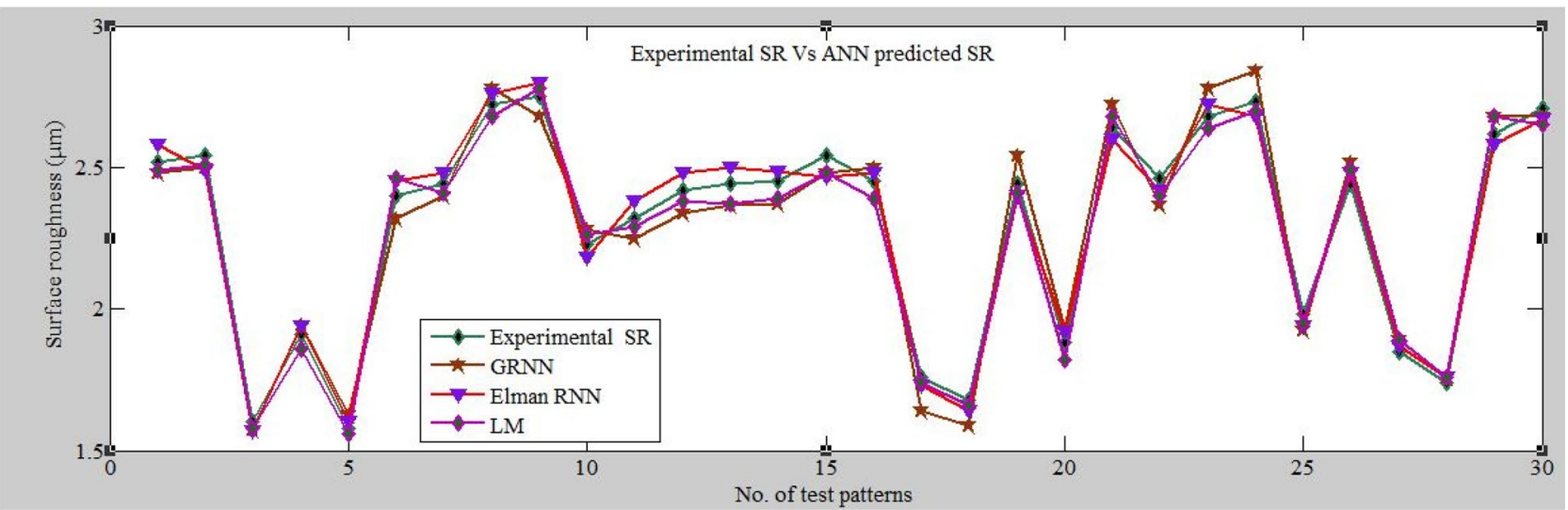

(b)

Fig. 21 Collation of experimental and predicted values by different FFBP-ANN models of a Nitinol alloy. a Material removal rate, $\mathbf{b}$ SR

Statistical validation measures like MSE, RMSE, MAE SD are more in generalized regression neural network.

2. LM training algorithm is the fastest back-propagation algorithm compared to the remaining two algorithms. LM with 5 neurons appeared to be the best ANN model with low statistical validation errors and good accuracy.

3. Elman regression neural network is another algorithm with better accuracy than generalized regression neural network and low accuracy than LM back-propagation neural network in terms of statistical measures perspective for anticipating WEDM responses.

4. ANFIS model with two Gaussian-type membership functions (gauss $\mathrm{mf}$ ) has been preferred for input attributes while constant-type membership function (MF) which is used for MRR and SR gives best results compared to gauss $2 \mathrm{mf}$ and gbell MF.

5. ANFIS model with two Gaussian MF was the best model amongst all neuro-fuzzy inference techniques (LM, Elman RNN, GRNN, gauss2MF, gbell MF) which was used for comparative purpose for predicting WEDM responses of Nitinol alloy.

From this investigation, it was concluded that ANFIS model gives more precise and useful soft computing approach when compared to ANN model for better prediction of WEDM machining responses like MRR and SR of Nitinol alloy.

Acknowledgements The authors would like to appreciate Kellogg's Research Labs, United States of America for supplying Nitinol alloy in rod form. They are also thankful to Defence Research and Development Laboratory, Hyderabad, India, for providing them with the necessary machine facilities of WEDM and for assistance during experiment. The authors thank Dr. P. Padaikathan, Senior Scientific Officer, 


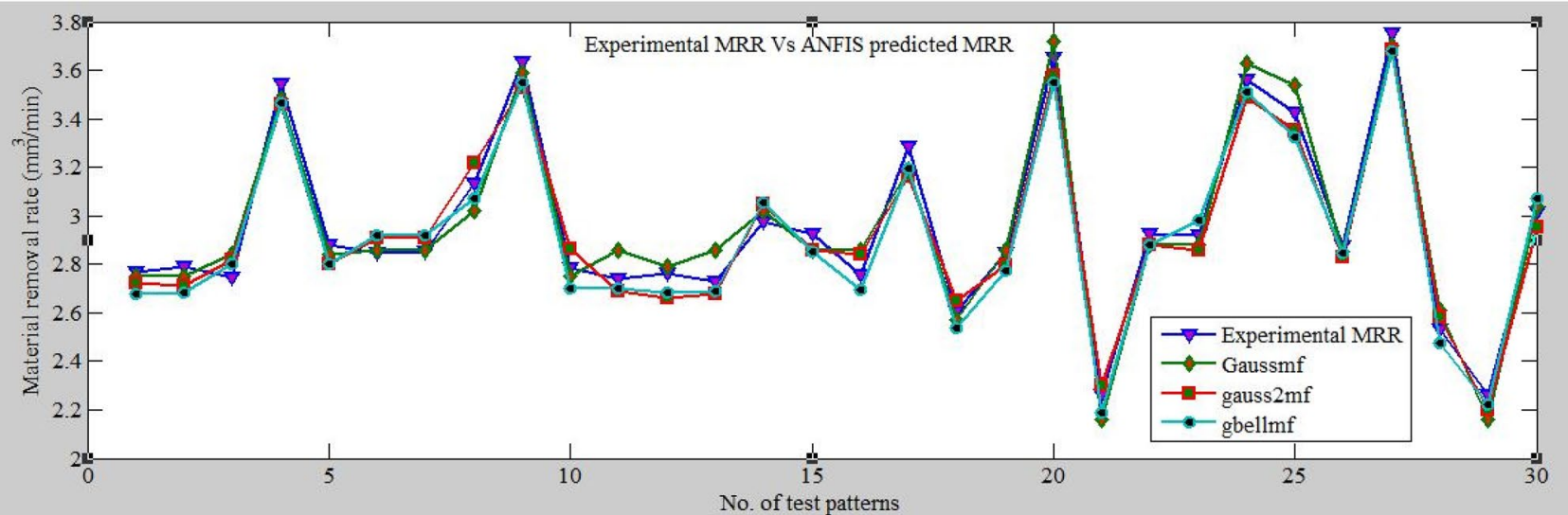

(a)

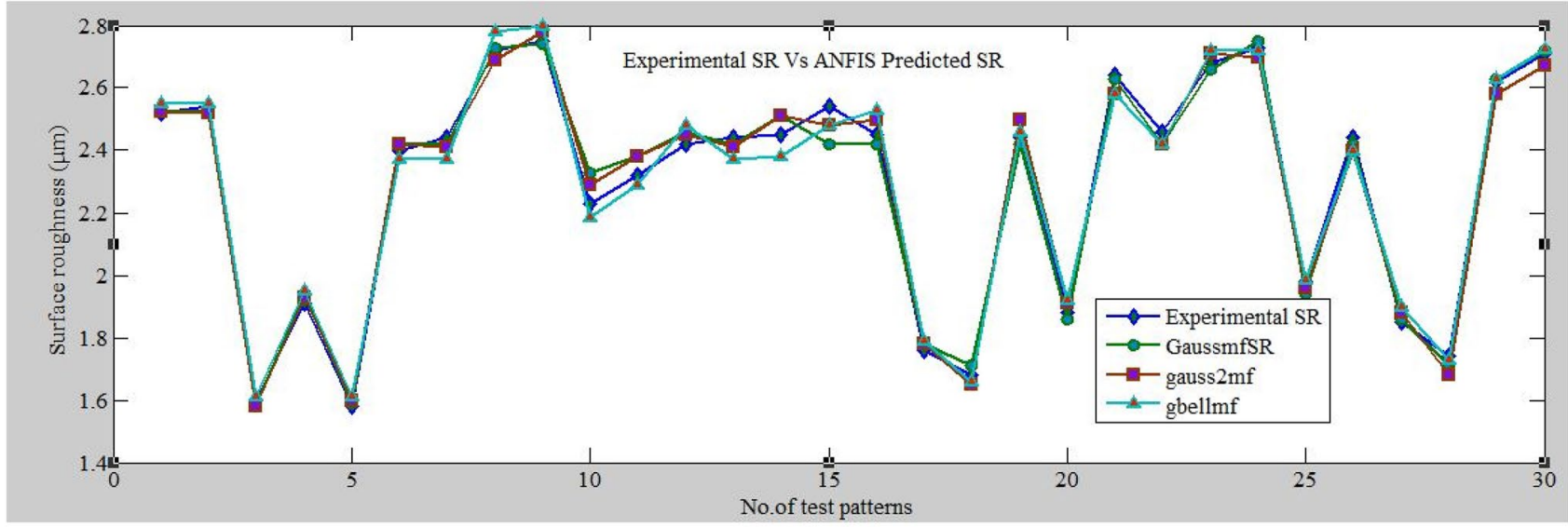

(b)

Fig. 22 Collation of experimental and predicted values by different ANFIS membership functions of a Nitinol alloy. a Material removal rate, b SR

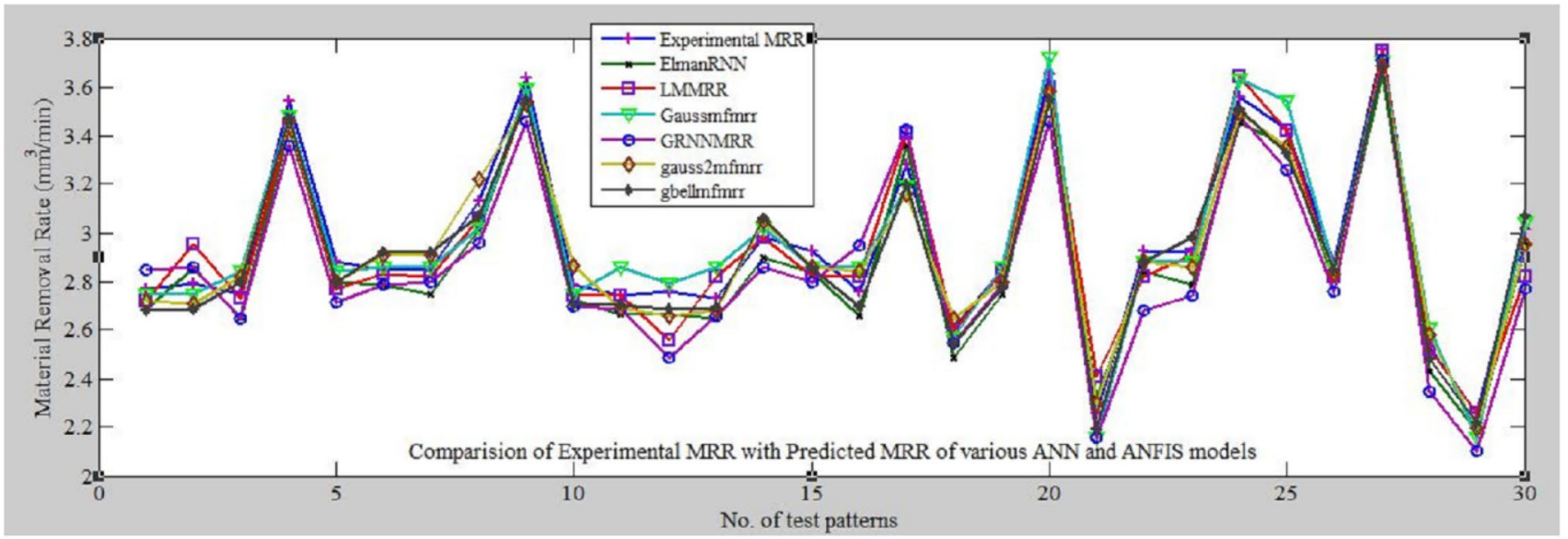

Fig. 23 Experimental and predicted values collation of MRR for ANN and adaptive neuro-FIS models 


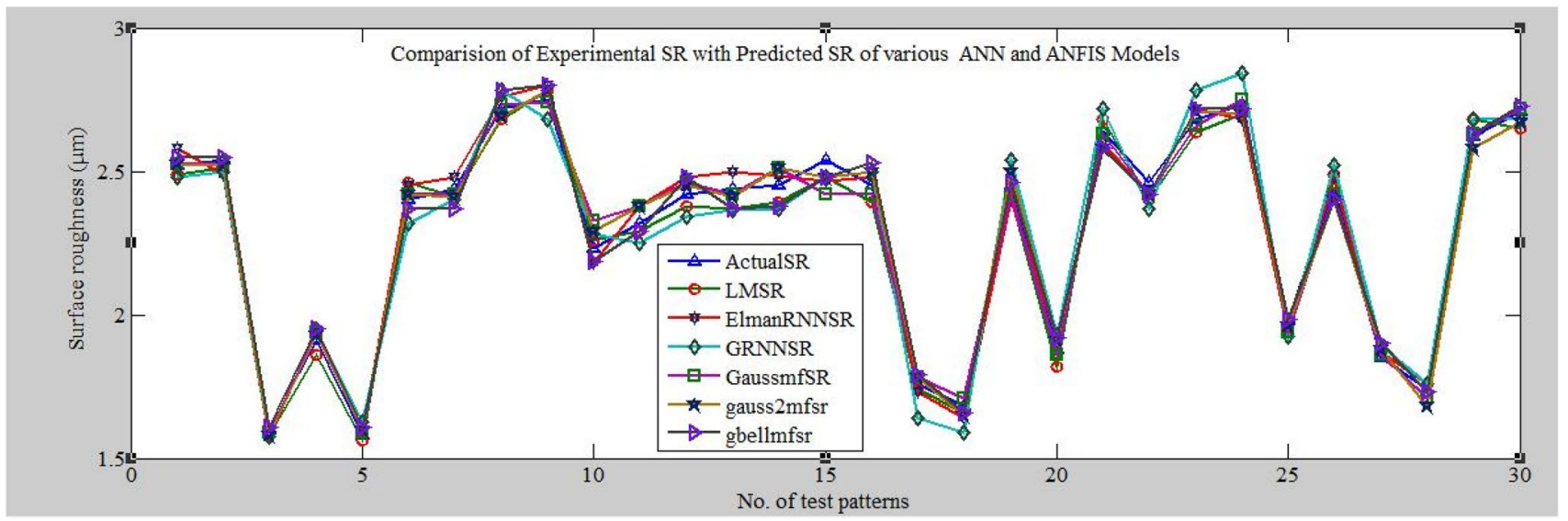

Fig. 24 Experimental and predicted values collation of SR for ANN and adaptive neuro-FIS models

Department of Material Science Engineering, Indian Institute of Science Bangalore, India, for getting DSC curve for the research work.

\section{Compliance with ethical standards}

Conflict of interest The author(s) declare that there is no conflict of interest in respect of research, authorship, and/or publication of this article.

\section{References}

1. Mathai VJ, Kumar S, Dave HK, Desai KP (2015) Machining/processing of shape memory alloys - a review recent advances in manufacturing

2. Srinivasan AV, McFarland DM (2002) Smart structures: analysis and design. Meas Sci Technol 13:1502-1503. https://doi. org/10.1088/0957-0233/13/9/710

3. Choudhury I, El-Baradie M (1998) Machinability of nickel-base super alloys: a general review. J Mater Processes Technol 77:278284. https://doi.org/10.1016/S0924-0136(97)00429-9

4. Liao YS, Yu YP (2004) Study of specific discharge energy in WEDM and its application. Int J Mach Tools Manuf 44:1373-1380. https ://doi.org/10.1016/j.ijmachtools.2004.04.008

5. Hasc A (2007) Electrical discharge machining of titanium alloy (Ti-6Al-4V). Appl Surf Sci 253:9007-9016. https://doi. org/10.1016/j.apsusc.2007.05.031

6. Narendranath S, Manjaiah M, Basavarajappa S, Gaitonde VN (2013) Experimental investigations on performance characteristics in wire electro discharge machining of $\mathrm{Ti}_{50} \mathrm{Ni}_{42.4} \mathrm{Cu}_{7.6}$ shape memory alloy. Proc Inst Mech Eng Part B J Eng Manuf 227:1180-1187. https://doi.org/10.1177/0954405413478771

7. Soni $\mathrm{H}$, Narendranath S, Ramesh MR (2018) Evaluation of wire electro discharge machining characteristics of $\mathrm{Ti}_{50} \mathrm{Ni}_{45} \mathrm{CO}_{5}$ shape memory alloy. J Mater Res 31:1801-1808. https://doi. org/10.1557/jmr.2017.137

8. Al Khaled A, Hosseini S (2015) Fuzzy adaptive imperialist competitive algorithm for global optimization. Neural Comput Appl 26:813-825. https://doi.org/10.1007/s00521-014-1752-4

9. Mukhopadhyay A, Barman TK, Sahoo P, Davim JP (2019) Modeling and optimization of fractal dimension in wire electrical discharge machining of EN 31 steel using the ANN-GA approach. Materials 12:1-13. https://doi.org/10.3390/ma12030454

10. Shivakoti I, Kibria G, Pradhan PM et al (2019) ANFIS based prediction and parametric analysis during turning operation of stainless steel 202. Mater Manuf Processes 34:112-121. https://doi. org/10.1080/10426914.2018.1512134

11. Singh NK, Singh Y, Kumar S, Sharma A (2019) Comparative study of statistical and soft computing-based predictive models for material removal rate and surface roughness during helium-assisted EDM of D3 die steel. SN Appl Sci. https://doi. org/10.1007/s42452-019-0545-X

12. Liang Z, Liao S, Wen Y, Liu X (2019) Working parameter optimization of strengthen waterjet grinding with the orthogonalexperiment-design-based ANFIS. J Intell Manuf 30:833-854. https://doi.org/10.1007/s10845-016-1285-z

13. Kumar S, Dhanabalan S, Narayanan CS (2019) Application of ANFIS and GRA for multi-objective optimization of optimal wire-EDM parameters while machining Ti-6Al-4V alloy. SN Appl Sci. https://doi.org/10.1007/s42452-019-0195-z

14. Shankar S, Mohanraj T, Rajasekar R (2019) Prediction of cutting tool wear during milling process using artificial intelligence techniques. Int J Comput Integr Manuf 32:174-182. https:// doi.org/10.1080/0951192X.2018.1550681

15. DuyTrinh N, Shaohui Y, Nhat Tan N et al (2019) A new method for online monitoring when grinding Ti-6Al-4V alloy. Mater Manuf Processes 34:39-53. https://doi.org/10.1080/10426 914.2018.1532587

16. Dewan MW, Huggett DJ, Liao TW et al (2016) Prediction of tensile strength of friction stir weld joints with adaptive neurofuzzy inference system (ANFIS) and neural network. Mater Des 92:288-299. https://doi.org/10.1016/j.matdes.2015.12.005

17. Gurupavan HR, Devegowda TM, Ravindra HV, Ugrasen G (2017) ScienceDirect estimation of machining performances in WEDM of aluminium based metal matrix composite material using ANN. Mater Today Proc 4:10035-10038. https://doi. org/10.1016/j.matpr.2017.06.316

18. Harsha N, Kumar IA, Raju KSR, Rajesh S (2018) ScienceDirect prediction of machinability characteristics of Ti6Al4V alloy using neural networks and neuro-fuzzy techniques. Mater Today Proc 5:8454-8463. https://doi.org/10.1016/j.matpr .2017.11.541

19. Pal SK, Chakraborty AED (2005) Surface roughness prediction in turning using artificial neural network. Neural Comput Appl 14:319-324. https://doi.org/10.1007/s00521-005-0468-x 
20. Metin H, Hasan E (2013) ANN- and ANFIS-based multi-staged decision algorithm for the detection and diagnosis of bearing faults. Neural Comput Appl 22:435-446. https://doi. org/10.1007/s00521-012-0912-7

21. Ali SM, Dhar NR (2010) Tool wear and surface roughness prediction using an artificial neural network (ANN) in turning steel under minimum quantity lubrication (MQL). World Acad Sci Eng Technol Int J Mech Mechatron Eng. https://doi.org/10.5281/zenodo.13324 88

22. Tsai K, Wang P (2001) Comparisons of neural network models on material removal rate in electrical discharge machining. J Mater Process Technol 117:111-124. https://doi.org/10.1016/S0924 -0136(01)01146-3

23. Kuo RJ, Cohen PH (1999) Multi-sensor integration for on-line tool wear estimation through radial basis function networks and fuzzy neural network. Neural Netw 12:355-370. https://doi.org/10.1016/ S0893-6080(98)00137-3

24. Zerti A, Yallese MA, Zerti $O$ et al (2019) Prediction of machining performance using RSM and ANN models in hard turning of martensitic stainless steel AISI 420. Proc Inst Mech Eng Part C J Mech Eng Sci 233:4439-4462. https://doi.org/10.1177/0954406218 820557

25. Zhang Y, Lei J (2017) Prediction of laser cutting roughness in intelligent manufacturing mode based on ANFIS. Proc Eng 174:82-89. https://doi.org/10.1016/j.proeng.2017.01.152

26. YusoffY, Zain AM, Haron H et al (2017) Orthogonal based ANN and multiGA for optimization on WEDM of Ti-48Al intermetallic alloys. Artif Intell Rev. https://doi.org/10.1007/s10462-017-9602-2

27. Esen $\mathrm{H}$, Esen M, Ozsolak O (2017) Modelling and experimental performance analysis of solar-assisted ground source heat pump system. J Exp Theor Artif Intell 29:1-17. https://doi.org/10.1080/09528 13X.2015.1056242

28. Esen $H$, Inalli M, Sengur A, Esen M (2008) Modelling a groundcoupled heat pump system using adaptive neuro-fuzzy inference systems. Int J Refrig 31:65-74. https://doi.org/10.1016/j.ijref rig.2007.06.007

29. Esen $H$, Inalli $M$, Sengur $A$, Esen $M(2008)$ Artificial neural networks and adaptive neuro-fuzzy assessments for ground-coupled heat pump system. Energy Build 40:1074-1083. https://doi. org/10.1016/j.enbuild.2007.10.002

30. Esen H, Inalli M, Sengur A, Esen M (2008) Forecasting of a groundcoupled heat pump performance using neural networks with statistical data weighting pre-processing. Int J Therm Sci 47:431-441. https://doi.org/10.1016/j.ijthermalsci.2007.03.004

31. Esen $H$, Inalli $M$, Sengur A, Esen M (2008) Performance prediction of a ground-coupled heat pump system using artificial neural networks. Expert Syst Appl 35:1940-1948. https://doi.org/10.1016/j. eswa.2007.08.081

32. Esen $H$, Inalli $M$, Sengur A, Esen M (2008) Predicting performance of a ground-source heat pump system using fuzzy weighted preprocessing-based ANFIS. Build Environ 43:2178-2187. https://doi. org/10.1016/j.buildenv.2008.01.002

33. Esen H, Ozgen F, Esen M, Sengur A (2009) Artificial neural network and wavelet neural network approaches for modelling of a solar air heater. Expert Syst Appl 36:11240-11248. https://doi. org/10.1016/j.eswa.2009.02.073

34. Esen $H$, Inalli $M$ (2010) ANN and ANFIS models for performance evaluation of a vertical ground source heat pump system. Expert Syst Appl 37:8134-8147. https://doi.org/10.1016/j. eswa.2010.05.074

35. Devarasiddappa D, George J, Chandrasekaran M, Teyi N (2016) Application of artificial intelligence approach in modeling surface quality of aerospace alloys in WEDM Process. Proc Technol 25:1199-1208. https://doi.org/10.1016/j.protcy.2016.08.239

36. Amirkhani S, Nasirivatan S, Kasaeian AB, Hajinezhad A (2015) ANN and ANFIS models to predict the performance of solar chimney power plants. Renew Energy 83:597-607. https://doi. org/10.1016/j.renene.2015.04.072

37. Singh NK, Singh Y, Kumar S, Sharma A (2019) Predictive analysis of surface roughness in EDM using semi-empirical, ANN and ANFIS techniques: a comparative study. Mater Today Proc. https://doi. org/10.1016/j.matpr.2019.08.234

38. D'Addona DM, Genna S, Leone C, Matarazzo D (2016) Prediction of poly-methyl-methacrylate laser milling process characteristics based on neural networks and fuzzy data. Proc CIRP 41:981-986. https://doi.org/10.1016/j.procir.2016.01.029

39. Wasserman PD (1989) Neural computing: theory and practice. Van Nostrand Reinhold Co., New York

40. Haykin S (1998) Neural networks: a comprehensive foundation, 2nd edn. Prentice Hall PTR, Upper Saddle River

41. Babajanzade Roshan S, Behboodi Jooibari M, Teimouri R et al (2013) Optimization of friction stir welding process of AA7075 aluminum alloy to achieve desirable mechanical properties using ANFIS models and simulated annealing algorithm. Int J Adv ManufTechnol 69:1803-1818. https://doi.org/10.1007/s0017 0-013-5131-6

42. Fard RK, Afza RA, Teimouri R (2013) Experimental investigation, intelligent modeling and multi-characteristics optimization of dry WEDM process of Al-SiC metal matrix composite. J Manuf Process. https://doi.org/10.1016/j.jmapro.2013.09.002

43. Taylan O, Karagözoğlu B (2009) An adaptive neuro-fuzzy model for prediction of student's academic performance. Comput Ind Eng 57:732-741. https://doi.org/10.1016/j.cie.2009.01.019

44. Sushmita Mitra YH (2000) Neuro-fuzzy rule generation: survey. IEEE Trans Neural Netw 11:748-768

45. Maher I, Eltaib MEH, Sarhan AAD (2014) Investigation of the effect of machining parameters on the surface quality of machined brass (60/40) in CNC end milling-ANFIS modeling. Int J Adv Manuf Technol 74:531-537. https://doi.org/10.1007/s00170-014-6016-z

46. Svalina I, Simunovic G, Simunovic K (2013) Machined surface roughness prediction using adaptive neurofuzzy inference system. Appl Artif Intell 27:803-817. https://doi.org/10.1080/08839 514.2013.835233

47. Shafaei R, Rabiee M, Mirzaeyan M (2011) An adaptive neuro fuzzy inference system for makespan estimation in multiprocessor nowait two stage flow shop. Int J Comput Integr Manuf 24:888-889. https://doi.org/10.1080/0951192X.2011.597430

48. Jyh-Shing JR (1997) Neuro-fuzzy and soft computing.pdf

49. Garg MP, Kumar A, Sahu CK (2017) Mathematical modeling and analysis of WEDM machining parameters of nickel-based super alloy using response surface methodology. Sadhana Acad Proc Eng Sci 42:981-1005. https://doi.org/10.1007/s12046-017-0647-3

50. Patowari PK, Saha P, Mishra PK (2010) Artificial neural network model in surface modification by EDM using tungsten-copper powder metallurgy sintered electrodes. Int J Adv Manuf Technol 51:627-638. https://doi.org/10.1007/s00170-010-2653-z

51. Panda DK (2010) Modelling and optimization of multiple process attributes of electrodischarge machining process by using a new hybrid approach of neuro-grey modeling. Mater Manuf Processes 25:450-461. https://doi.org/10.1080/15394450902996551

52. Kumar S, Batish A, Singh R, Singh TP (2014) A hybrid Taguchi-artificial neural network approach to predict surface roughness during electric discharge machining of titanium alloys. J Mech Sci Technol 28:2831-2844. https://doi.org/10.1007/s12206-014-0637-x 
53. Unune DR, Mali HS (2016) Artificial neural network-based and response surface methodology-based predictive models for material removal rate and surface roughness during electro-discharge diamond grinding of Inconel 718. Proc Inst Mech Eng Part B J Eng Manuf 230:2081-2091. https://doi.org/10.1177/095440541561934 7
Publisher's Note Springer Nature remains neutral with regard to jurisdictional claims in published maps and institutional affiliations. 